\title{
An Experimental Study of Roughness-Induced Instabilities in a Supersonic Boundary Layer
}

\author{
Michael A. Kegerise, Rudolph A. King $†$ Meelan Choudhari; Fei Li \\ NASA Langley Research Center, Hampton, VA 23681
}

\begin{abstract}
Progress on an experimental study of laminar-to-turbulent transition induced by an isolated roughness element in a supersonic laminar boundary layer is reported in this paper. Here, the primary focus is on the effects of roughness planform shape on the instability and transition characteristics. Four different roughness planform shapes were considered (a diamond, a circle, a right triangle, and a $45^{\circ}$ fence) and the height and width of each one was held fixed so that a consistent frontal area was presented to the oncoming boundary layer. The nominal roughness Reynolds number was 462 and the ratio of the roughness height to the boundary layer thickness was 0.48. Detailed flow-field surveys in the wake of each geometry were performed via hot-wire anemometry. High- and low-speed streaks were observed in the wake of each roughness geometry, and the modified mean flow associated with these streak structures was found to support a single dominant convective instability mode. For the symmetric planform shapes - the diamond and circular planforms-the instability characteristics (mode shapes, growth rates, and frequencies) were found to be similar. For the asymmetric planform shapes - the right-triangle and $45^{\circ}$ fence planformsthe mode shapes were asymmetrically distributed about the roughness-wake centerline. The instability growth rates for the asymmetric planforms were lower than those for the symmetric planforms and therefore, transition onset was delayed relative to the symmetric planforms.
\end{abstract}

\section{Nomenclature}

$E_{o} \quad$ output voltage of hot-wire anemometer

$k$ height of roughness element

$L \quad$ hot-wire calibration coefficient (see Eq. 1)

$m \quad$ streamwise mass flux, $\rho u$

$M \quad$ hot-wire calibration coefficient (see Eq. 1)

$p_{o 2} \quad$ post normal shock total pressure

$R e_{k}$ Reynolds number based on roughness height $k$ and local conditions in the undisturbed laminar boundary layer at the height $k$

$T_{a w}$ adiabatic wall temperature

$T_{c} \quad$ total temperature during hot-wire calibration

$T_{o} \quad$ total temperature

$T_{w} \quad$ wall temperature

$u \quad$ streamwise velocity

$w \quad$ width of roughness element

$x \quad$ streamwise position from model leading edge

$x_{n} \quad$ streamwise position from nozzle throat

$y \quad$ wall-normal position above model surface

$z \quad$ spanwise position relative to the model centerline

\footnotetext{
${ }^{*}$ Research Scientist, Flow Physics and Control Branch, M. S. 170. Senior Member AIAA.

$\dagger$ Research Scientist, Flow Physics and Control Branch, M. S. 170. Member AIAA.

$¥$ Aerospace Technologist, Computational Aerosciences Branch, M. S. 128. Associate Fellow AIAA.

$\S$ Aerospace Technologist, Computational Aerosciences Branch, M. S. 128.

${ }^{\top}$ Aerospace Technologist, Hypersonic Airbreathing and Propulsion Branch. Senior Member AIAA.
} 
Superscript

$n$ hot-wire calibration exponent (see Eq. 1)

() mean value

( ) $)^{\prime}$ r.m.s. value

\section{Introduction}

GURFACE roughness is known to dominate the laminar-to-turbulent transition process on many high-speed Nvehicles. That roughness can be either distributed, such as an array of thermal protection system tiles, or it can be isolated, in the form of protruding elements above or cavities below the outer mold line of a vehicle. In the case of reentry vehicles, isolated roughness is of particular concern because it can cause transition at a Mach number much higher than expected, leading to high local heating levels and asymmetric aerodynamic loads on the vehicle. ${ }^{1}$ Alternatively, for hypersonic air-breathing propulsion systems, turbulent flow at the scramjet inlet is desired to mitigate engine unstart. ${ }^{2}$ To ensure a turbulent flow in that case, a spanwise periodic array of isolated roughness elements on the vehicle forebody can be used to force laminarto-turbulent transition. In either case, accurate prediction tools for roughness-induced transition are critical to vehicle design, performance, and safety.

The state-of-the-art approach for prediction of transition induced by an isolated roughness is to utilize engineering correlations based on a critical roughness Reynolds number such as $R e_{k} \cdot{ }^{3,4}$ While this approach can be effective, there are several limitations. In particular, correlations are applicable only to the geometry for which they were developed, they often exhibit large data scatter which produces large uncertainty in the predicted transition location, and they offer no physical insight into the instability and transition mechanisms. An alternative approach, one which should afford greater accuracy in our transition predictions, is to develop prediction methodologies that are based on the underlying physical mechanisms associated with isolated roughness-induced transition. To that end, we must first determine how an isolated roughness causes transition in a high-speed boundary layer.

Schneider recently reviewed the existing experimental ground-based and flight studies of high-speed roughness-induced transition. ${ }^{4}$ Most of those studies, which were performed over the past 50 years, were focused on surface-based measurements of transition location and parametric effects on roughness-induced transition. The roughness Reynolds number, $R e_{k}$, which is based on undisturbed conditions at the height of the roughness, was identified as the chief parameter affecting roughness-induced transition, but Mach number, wall temperature, pressure gradient, roughness shape, and the freestream disturbance environment also play an important role. These past studies have been useful for identifying the key parametric trends, but they do little to reveal the physical mechanisms of roughness-induced transition. In recent years, there have been numerous direct numerical simulations (DNS) of isolated roughness-induced transition in high-speed flows $^{5-13}$ and a new generation of experiments have focused on obtaining off-body flow-field measurements and visualizations in the wakes of isolated roughness elements. ${ }^{14-19}$ The DNS studies, which considered a range of roughness-element geometries and both supersonic and hypersonic Mach numbers, have provided useful insights into the transition mechanisms in the roughness wake. Specifically, for roughness elements submerged within the boundary layer, we generally observe a system of initially steady streamwise vortices extending downstream from the roughness element. Through the lift-up mechanism, these vortices redistribute the streamwise momentum to form high- and low-speed streak structures in the wake. The modified mean flow associated with these streaks then supports convective instabilities that grow with streamwise position and eventually cause breakdown to turbulence. The DNS studies of Redford et al. ${ }^{6}$ and Bernardini et al. ${ }^{10}$ indicate that this transition mechanism holds across the speed range, from subsonic to hypersonic Mach numbers, although transition onset is delayed as the Mach number increases - a well known parametric trend from previous experimental observations. Redford et al. also observed transition delay with decreasing wall temperature. 
Given the convective nature of the roughness-wake instabilities, it is expected that isolated roughnessinduced transition will be sensitive to the freestream disturbance environment. That sensitivity was observed in the DNS of Balakumar and Kegerise ${ }^{12}$ and Redford et al. ${ }^{6}{ }^{6}$ where acoustic disturbances were imposed on the freestream. These disturbances enter the boundary layer, are scattered by the roughness element, and subsequently excite instabilities in the roughness wake. Increasing the acoustic disturbance amplitude was found to move the transition onset point forward in both studies, but the essential transition mechanisms did not appear to be altered - at least for the range of amplitudes considered. Similarly, the PSE computations of roughness-wake instabilities by Choudhari et al. ${ }^{5}$ show the upstream shift in transition onset location with increasing initial amplitude. The sensitivity to the freestream disturbance environment was also observed in the experimental studies of Borg and Schneider ${ }^{20}$ and Casper et al. ${ }^{21}$ in the Boeing-AFOSR Mach 6 Quiet Tunnel at Purdue University, and by Kegerise et al. ${ }^{14}$ in the NASA Langley Supersonic Low Disturbance Tunnel. In each of those studies, transition onset due to roughness was delayed for quiet-flow conditions relative to that for noisy-flow conditions. As such, roughness-induced transition studies should generally be conducted in quiet-flow environments, especially if the ground-based data is to be extrapolated to flight conditions where the freestream disturbance levels are expected to be low. Perhaps one exception to this can be found in the experimental study of Wheaton and Schneider. ${ }^{17}$ There, they considered a slender cylindrical roughness element with $k / \delta \approx 1$ and $k / D=2$ in the laminar boundary layer of their Mach 6 quiet nozzle. A narrowband oscillation was observed in both the wake of the cylinder and in the separated flow region upstream of the cylinder. Subsequent DNS by Chang et al. ${ }^{22}$ and Bartkowicz et al. ${ }^{7}$ revealed a self-sustained oscillation associated with a vortex-shock interaction in the separated region upstream of the cylinder that feeds disturbances into the roughness wake and ultimately leads to breakdown. In that case, where a limit-cycle oscillation drives the wake instabilities, the freestream disturbance environment may be less important.

If we focus our attention on roughness elements that are submerged in the boundary layer $(k / \delta \sim 0.5)$ with a spanwise length scale roughly greater than or equal to the boundary-layer thickness, the current DNS studies suggest that transition in the roughness wake is driven by convective instabilities. In that case, Choudhari et al..$^{5,11,23}$ suggest an examination of the spatial stability of the modified mean flow in the roughness wake as a potential approach for prediction of transition. Once the relevant instability modes are identified, the growth rates can be integrated to determine which ones are most likely to dominate the transition process, and $\mathrm{N}$-factors may be correlated to measurements of the transition location. Following this approach, Choudhari et al. performed Navier-Stokes computations of the flow past an isolated roughness element in both Mach 3.5 and 5.9 laminar boundary layers. There, the focus was on a roughness element with a diamond planform shape and a moderate height ( $k / \delta$ of about one half). The computations for this configuration revealed high- and low-speed streaks embedded in the wake of the roughness element that persist for a long distance downstream. Through a spatial stability analysis, the wake flow was found to support both even (varicose) and odd (sinuous) modes of convective instabilities that experience strong enough growth to cause transition. The relative growth of the instability modes was found to depend on the specifics of the roughness geometry (e.g. roughness height and spanwise length scale) and flow conditions (e.g. Mach number and wall temperature).

To verify the existence of the embedded streaks and their instability modes, Kegerise et al. ${ }^{16}$ performed off-body mean and dynamic flow-field measurements in the downstream wake of a diamond planform roughness element in a Mach 3.5 laminar boundary layer. In that study, the test geometry was a flat plate with a sharp leading edge. To minimize the influence of freestream disturbances on the measurements, the experiment was conducted in the NASA Langley Supersonic Low Disturbance Tunnel (SLDT), which is a quiet wind tunnel facility with root-mean-square (r.m.s.) static pressure fluctuations that are less than $0.05 \%$ of the mean static pressure. The experimental measurements, which included hot-wire and pitot-probe surveys, confirmed the existence of the embedded high- and low-speed streaks in the roughness wake. Furthermore, the measurements indicated the presence of both even and odd modes of instability, although their relative magnitude was found to depend on the specifics of the roughness geometry and flow conditions.

Our previous experimental studies, as indicated in the paragraph above, were primarily focused on a single planform geometry. To provide additional insight to the instability mechanisms associated with isolated roughness-induced transition, we have developed a new experimental data set that examines the effects of roughness planform shape. In this paper, we report on the detailed flow-field surveys that comprise this new data set. 


\section{Experimental Details}

\section{A. Wind-Tunnel Facility}

The experimental measurements were performed in the Supersonic Low-Disturbance Tunnel (SLDT) at the NASA Langley Research Center. This "quiet" wind tunnel facility produces a Mach 3.5 freestream with r.m.s. static pressure fluctuations that are less than $0.05 \%$ of the mean static pressure. Since boundary-layer transition is known to be sensitive to the disturbance environment, testing in a low-noise facility, such as the SLDT, is necessary to simulate transition in the low-disturbance environment encountered during high-altitude flight. Details on the facility operation and performance characteristics are provided in Beckwith et al. ${ }^{24}$ and Chen. ${ }^{25}$ For the current experiment, the facility was configured with a Mach 3.5 two-dimensional rapid-expansion nozzle and typical nozzle performance characteristics are shown in Fig. 1. Here, the fluctuating pitot pressure r.m.s. (in a frequency band from $100 \mathrm{~Hz}$ to $100 \mathrm{kHz}$ ) and the Mach number variation along the nozzle centerline are shown for different freestream unit Reynolds numbers. The abscissa in both plots denotes the distance from the nozzle throat, and the
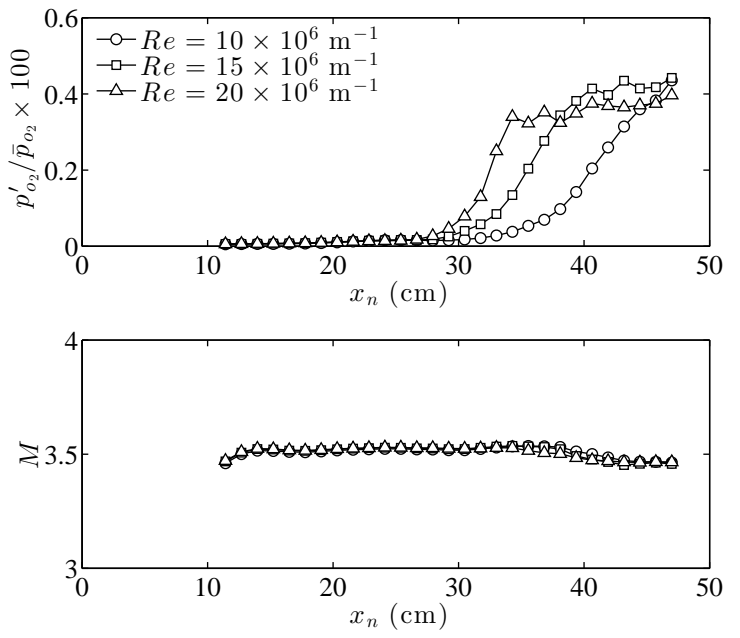

Figure 1. Fluctuating pitot pressure r.m.s. (normalized by the mean pitot pressure) and Mach-number distribution along the centerline of the Mach 3.5 twodimensional rapid-expansion nozzle. nozzle exit is at $39.4 \mathrm{~cm}$. The uniform quiet-flow core of the nozzle begins at the point where the freestream reaches the design Mach number of 3.5 and generally ends at the point where the freestream disturbance levels reach $0.05 \%$. Therefore, at a nominal test unit Reynolds number of $10 \times 10^{6} \mathrm{~m}^{-1}$, the uniform quiet-flow core is seen to start at $14 \mathrm{~cm}$ and to end at approximately $35 \mathrm{~cm}$.

\section{B. Wind-Tunnel Model and Roughness Elements}

The wind-tunnel model was a flat plate machined from 15-5 stainless steel. As shown in the schematic diagram of Fig. 2, the flat plate is $406.4 \mathrm{~mm}$ long, $228.6 \mathrm{~mm}$ wide at the leading edge, and tapers symmetrically to $76.2 \mathrm{~mm}$ wide at the trailing edge. The leading edge has a $15^{\circ}$ bevel on the bottom side of the plate and a nominal leading-edge thickness of $60 \mu \mathrm{m}$. The trapezoidal shape of the flat plate was designed to alleviate nozzle side wall blockage effects that were identified in earlier testing with a rectangular flat plate model. The top surface of the flat plate was polished to a roughness level of $0.025 \mu \mathrm{m} \mathrm{r.m.s.} \mathrm{(as} \mathrm{measured}$ with a surface-contact profilometer) and had no visible scratches at 3 times magnification. The flat plate was instrumented with 15 type-K thermocouples, positioned along the model centerline, for measurement of the surface temperature. When installed in the SLDT, the leading edge of the model was positioned on the nozzle centerline, $14 \mathrm{~cm}$ downstream from the nozzle throat. At that position, and a nominal test unit Reynolds number of $10 \times 10^{6} \mathrm{~m}^{-1}$, quiet flow with a constant Mach number of 3.5 extends over the first 21 $\mathrm{cm}$ of the model.

The isolated roughness elements used in our experimental study were fabricated from a low compressibility polyester shim stock material that is easily cut into arbitrary planforms via laser ablation. The roughness elements were then attached to the model surface with cyanoacrylate adhesive. Four different roughness elements, each with a different planform shape, were considered in our study. As shown in the schematic diagram of Fig. 3, two of the roughness elements (diamond and circle) have a symmetric planform geometry and the other two (right triangle and fence, both with an upstream edge inclined $45^{\circ}$ to the flow) have an asymmetric planform geometry. The spanwise width of each roughness element was held fixed at $3.6 \mathrm{~mm}$ and the nominal height of each element, which was measured in situ with a surface-contact profilometer, was $346.0 \pm 3.0 \mu \mathrm{m}$. This presents a consistent frontal area or blockage to the oncoming flow for all of the roughness cases. When attached to the model surface, each roughness element was centered on the model 


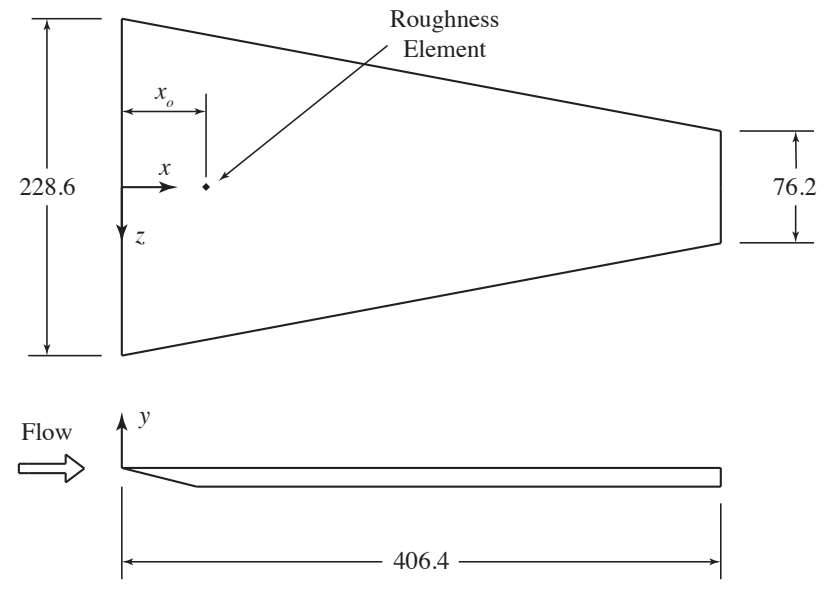

Figure 2. Schematic of flat-plate model (not to scale). Dimensions in $\mathrm{mm}$.

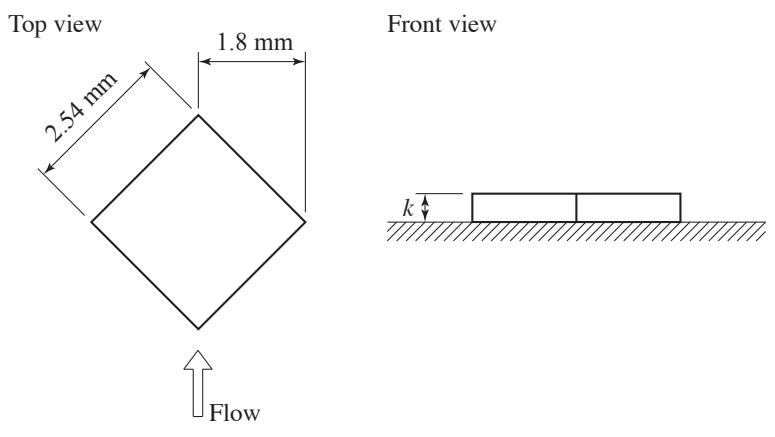

(a) Diamond roughness element. $k=347.0 \mu \mathrm{m}$.

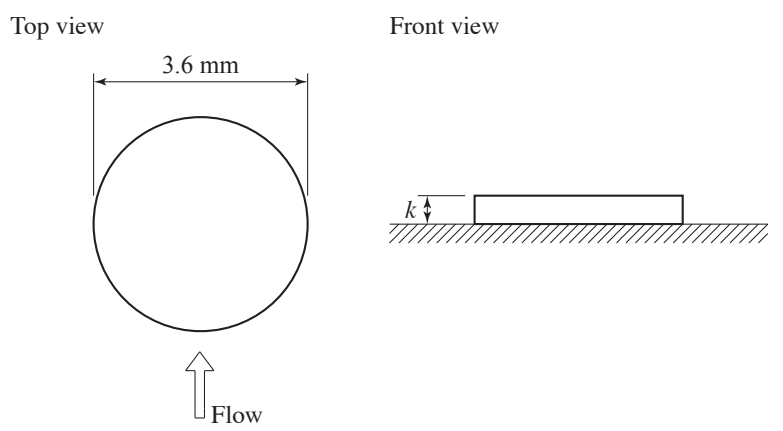

(b) Circular roughness element. $k=346.1 \mu \mathrm{m}$.

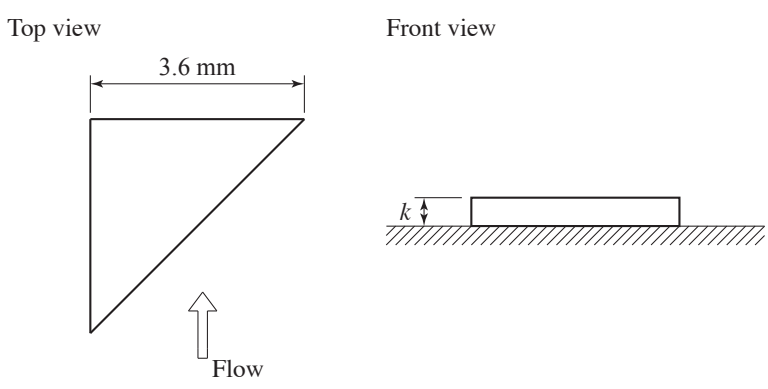

(c) Right triangle roughness element. $k=344.5 \mu \mathrm{m}$.

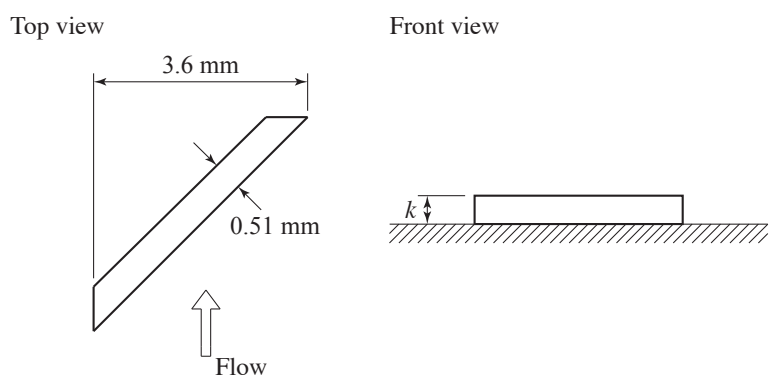

(d) $45^{\circ}$ fence roughness element. $k=346.6 \mu \mathrm{m}$.

Figure 3. Schematic of isolated roughness elements with different planform shapes. The nominal height for all roughness elements was $346.0 \pm 3.0 \mu \mathrm{m}$. Each roughness element was centered on the model centerline and the front edge of each roughness element was positioned $39.7 \mathrm{~mm}$ from the model leading edge. 
centerline and the front edge was positioned $39.7 \mathrm{~mm}$ downstream from the model leading edge.

\section{Hot-Wire Anemometry}

A miniature hot-wire probe was used to measure the mean and fluctuating streamwise mass-flux in the roughness-element wake. The hot-wire probe was operated in a constant-temperature mode at a high overheat ratio where the output is primarily sensitive to mass-flux fluctuations, and total-temperature fluctuations can be neglected. ${ }^{26}$ The hot-wire sensors were platinum-plated tungsten wire, with a $3.8 \mu \mathrm{m}$ diameter and a $0.5 \mathrm{~mm}$ nominal length (length-to-diameter ratio of 132), welded to the ends of the hot-wire prongs. The wires were always mounted with slack to avoid strain-gauging effects. Square-wave injection was used to obtain an optimally flat frequency response for the hot-wire sensors, and the $-3 \mathrm{~dB}$ cutoff frequency was typically $270 \mathrm{kHz}$.

For calibration, the hot-wire probe was positioned in the freestream of the SLDT and exposed to a massflux range that covers the range expected during a survey of the roughness-element wake. The mass-flux calibration data were then fit to a curve of the form:

$$
E_{o}^{2}=L+M(m)^{n},
$$

where $E_{o}$ is the anemometer output voltage, $m$ is the streamwise mass flux, and $L, M$, and $n$ are chosen to give the best fit in a least-squares sense. Generally, Eq. 1 is only applicable to hot-wire data collected at the same total temperature for which the calibration was developed. Therefore, when performing a survey of the roughness-element wake, where the mean total temperature varies across the wake, a temperature correction must be employed. To that end, we utilized a new curve fit of the form:

$$
E_{o}^{2}\left(T_{o} / T_{c}\right)=L+M(m)^{n},
$$

where the output voltage is scaled by $\sqrt{T_{o} / T_{c}}$. Here, $T_{o}$ is the mean total temperature at which $E_{o}$ was measured and $T_{c}$ is the nominal total temperature at which the mass-flux calibration was performed. Measurements of the mean total temperature were obtained from unheated wire surveys of the flow. By measuring the unheated wire resistance, and utilizing a calibration of the wire recovery factor versus the wire Reynolds number, the total-temperature can be calculated. Further details on the hot-wire probe design, calibration procedure, and data reduction can be found in Kegerise et al. ${ }^{14}$

To position the hot-wire probe in the roughness-element wake, we utilized a 3 -axis traverse system mounted to the tunnel test section ceiling. The positioning accuracies in the streamwise, spanwise, and wall-normal directions were $\pm 26 \mu \mathrm{m}, \pm 16 \mu \mathrm{m}$, and $\pm 8 \mu \mathrm{m}$ respectively.

\section{Data Acquisition and Processing}

The output voltage from the hot-wire anemometer was AC coupled, pre-amplified, and band-pass filtered between $1 \mathrm{kHz}$ and $400 \mathrm{kHz}$. The output of the filter was then sampled with a 16-bit A/D at $1 \times 10^{6} \mathrm{samples} / \mathrm{sec}$. One million samples were acquired for each position in a roughness-wake survey. The output voltage from the anemometer was also DC coupled and passed through a low-pass filter with a cut-off frequency of $20 \mathrm{~Hz}$. The output of that filter was then passed to a digital multimeter for measurement of the mean hot-wire voltage. For the unheated wire surveys, the wire resistance was measured with a digital multimeter. Using the measured total hot-wire voltage (mean plus fluctuating components), the measured unheated wire resistance, and the hot-wire calibration, an iterative procedure was employed to obtain the instantaneous mass flux. ${ }^{14}$ The mass-flux time series were subsequently processed to obtain the mean mass-flux, the broadband r.m.s. mass flux, and the mass-flux power spectral density (PSD). For the PSD estimates, the mass-flux time series were processed in blocks of 5000 points with a Hanning window and $50 \%$ overlapping. In total, 400 block averages were performed and the frequency resolution of the spectral estimates was $\Delta f=200 \mathrm{~Hz}$.

\section{Results}

For each roughness planform geometry, detailed hot-wire and unheated-wire surveys of the roughness wake were performed. These surveys included $y$ - $z$ planes at several streamwise stations along the roughness wake. At each station, data were collected in spanwise increments of $\Delta z=0.2 \mathrm{~mm}$ and confined to a region between $z \pm 3.6 \mathrm{~mm}$. In the wall-normal direction, data were collected at approximately 18 heights 


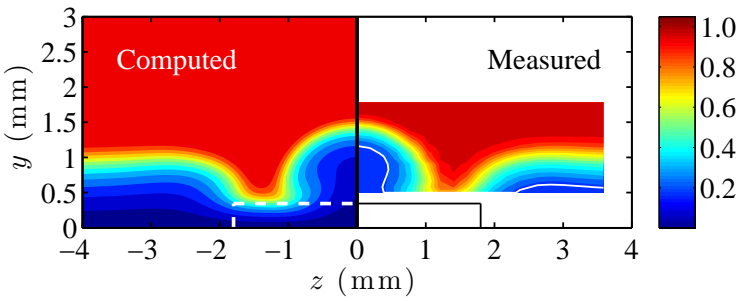

(a) Mean mass flux at $x=110.6 \mathrm{~mm}$.

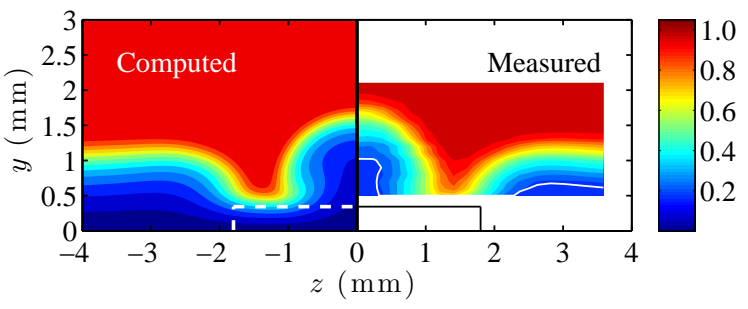

(c) Mean mass flux at $x=136.5 \mathrm{~mm}$.

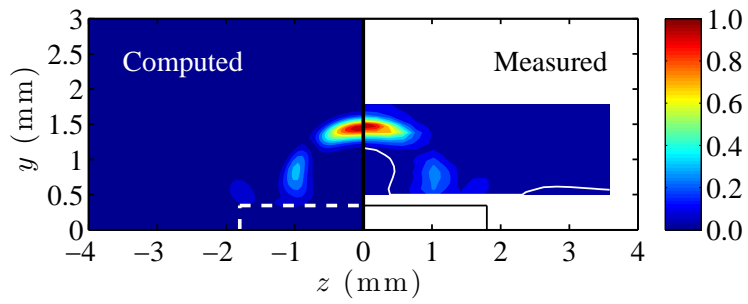

(b) R.M.S. mass flux at $f=120 \mathrm{kHz}$ and $x=110.6 \mathrm{~mm}$.

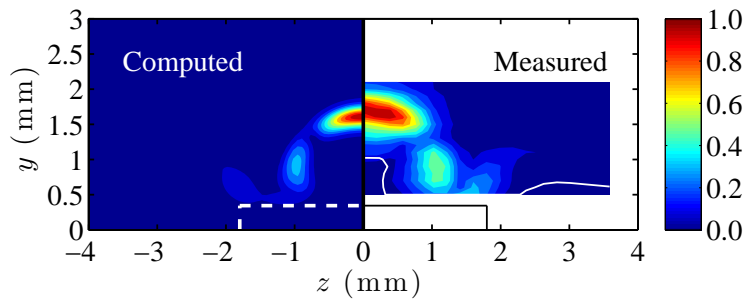

(d) R.M.S. mass flux at $f=120 \mathrm{kHz}$ and $x=136.5 \mathrm{~mm}$.

Figure 4. (a),(c) Comparison of the measured and computed mean mass flux $\left(\bar{m} / m_{e}\right)$ at two streamwise stations in the diamond roughness element wake. (b),(d) Comparison of the measured r.m.s. mass flux $\left(\mathrm{m}^{\prime} / \mathrm{m}_{\max }^{\prime}\right)$ at $f=120 \mathrm{kHz}$ and the computed eigenfunction for even mode $\mathbf{I}$ at the same frequency.

in increments of $\Delta y=0.08 \mathrm{~mm}$ or $0.1 \mathrm{~mm}$. For the diamond and circular planform geometries, wall-normal profiles along the wake centerline were also collected. All surveys were performed at a freestream unit Reynolds number of $10.8 \times 10^{6} \mathrm{~m}^{-1}$ and a nominal freestream total temperature of $319.3 \mathrm{~K}$. The measured wall temperature at these test conditions was $290 \mathrm{~K}$, which is slightly above the adiabatic wall temperature $\left(T_{w} / T_{a w} \approx 1.03\right)$. Presumably, this is due to shock-induced heating on the back side of the flat plate model. For the chosen test conditions, the smooth wall boundary layer was laminar and essentially two dimensional over the survey region. ${ }^{16}$ Furthermore, linear-stability predictions indicate that smooth-wall transition due to first-mode instability is not expected to occur on the model. ${ }^{5}$ Smooth wall boundary layer surveys with the hot-wire probe confirmed this and in fact, first-mode instabilities were not detected over the region surveyed. The roughness Reynolds number, $R e_{k}$, which is based on undisturbed conditions at the height of the roughness, was 462 , and the ratio of the roughness height to boundary-layer thickness was $k / \delta=0.48$. Both of these roughness parameters were based on a Mach 3.5 flat plate similarity solution at the streamwise location of the roughness element.

\section{A. Diamond Roughness Element}

Measurements and preliminary stability calculations in the wake of the diamond roughness element were previously reported in Kegerise et al. ${ }^{16}$ Here, we provide a brief review of those results and present a comparison between the measurements and recent stability calculations. Mean mass-flux contours at two streamwise stations are shown in Figs. 4a and 4c. On the left side of each figure, the computed mean mass-flux is shown. These planar contours were extracted from a compressible Naiver-Stokes computation of the laminar flow around and downstream of the roughness element. ${ }^{16}$ On the right side of each figure, the measured mean mass-flux is presented. In both cases, the mass-flux values were normalized by the mass-flux at the boundary-layer edge, $m_{e}$. The solid-black and dashed-white lines at the bottom center of each figure represent the projected outline of the roughness element and the solid white line in each figure denotes a Mach 1.2 contour line. Data below that line should be taken as qualitative due to transonic effects on the hot-wire response. ${ }^{27}$

Generally, the measured and computed mean mass-flux contours share the same flow features. Specifically, along the centerline of the roughness-element wake, low-speed fluid is lifted away from the wall and a lofted shear layer is formed. On either side of this low-speed region, and just inboard of the roughness-element edges, high-speed fluid is pushed down toward the wall and the boundary layer becomes very thin relative to 


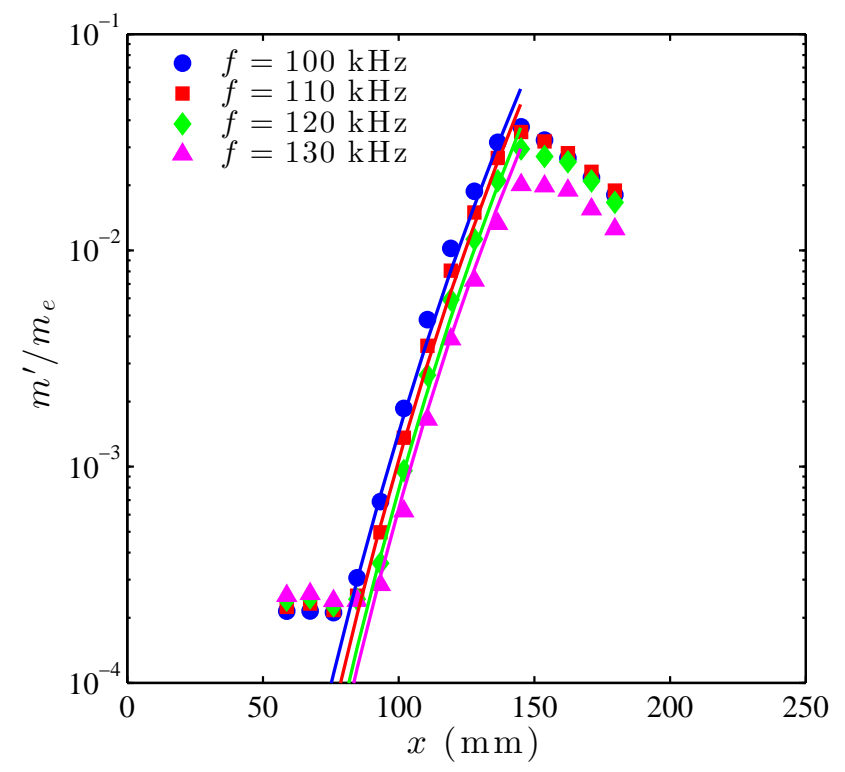

Figure 5. Streamwise evolution of peak r.m.s. mass-flux fluctuations $\left(\mathrm{m}^{\prime} / \mathrm{m}_{e}\right)$ in the diamond roughness element wake. The symbols denote measured data at selected frequencies and the solid lines denote the integrated amplitudes from the stability calculations for even mode I. For each frequency shown, the stability results were scaled to the amplitudes of the measured data at $x=93.3 \mathrm{~mm}$.

the smooth wall boundary layer. As we move away from the roughness centerline in the spanwise direction, the boundary layer approaches its undisturbed state. This flow structure persists for hundreds of roughness heights downstream until breakdown to transition begins. The footprint of these low- and high-speed regions is often observed as streaks in wall-based measurements of heat flux and skin friction downstream of an isolated roughness element. ${ }^{28,29}$

For the first streamwise station of $x=110.6 \mathrm{~mm}$, where the mean flow is laminar, the agreement between the measurements and computations is very good. For the second streamwise station of $x=136.5 \mathrm{~mm}$, however, we begin to observe clear quantitative differences between the computed laminar flow and the measurements. Here, the wake flow is in the beginning states of breakdown and the Reynolds stresses associated with the transitional flow have reached large enough levels to modify the mean flow. This behavior is not, of course, captured by the laminar-flow computations. Nevertheless, in the laminar region of the flow, the overall agreement between the measured and computed mean flow is quite good, and that gave us confidence to proceed with the stability calculations.

The spatial stability of the computed roughness wake was examined at several streamwise stations using the methodology described in $\mathrm{Li}$ and Choudhari. ${ }^{30}$ Since the wall-normal and spanwise scales of the flow in the roughness wake are comparable, the modified boundary-layer flow has a strongly inhomogeneous character in both the $y$ and $z$ directions. Therefore, a planar, partial-differential eigenvalue problem was solved to predict the instability characteristics in the wake. In that analysis, both even (varicose) and odd (sinuous) modes of instability were examined. The growth rates for each relevant family of modes were then integrated in the streamwise direction to determine which modes are likely to dominate within the wake. For the current flow conditions and diamond planform geometry, one of the instability modes, herein referred to as even mode I, received an order of magnitude more growth than any other mode. It is therefore expected that this mode will dominate the transition process for this case.

The computed eigenfunctions of even mode I are shown on the left side of Figs. $4 \mathrm{~b}$ and $4 \mathrm{~d}$ for two streamwise stations and a frequency of $120 \mathrm{kHz}$. On the right side of the figures, the measured r.m.s. mass flux at $120 \mathrm{kHz}$ is shown. Here, the r.m.s. mass flux was determined for each point in the survey by integrating the PSD over a $\pm 1 \mathrm{kHz}$ frequency band about the frequency of interest. The resulting values were then normalized by the maximum r.m.s. mass flux in the survey plane at this same frequency. Generally, the spatial distribution of the measured disturbance amplitude is similar to the spatial distribution of the 
even mode I eigenfunction. Both display peak amplitudes in regions of high wall-normal and spanwise shear, with the maximum peak along the centerline of the roughness wake. While only one frequency is shown here for brevity, the spatial distribution of the measured r.m.s. mass flux and the computed even mode I eigenfunction where found to be similar over a broad range of frequencies, suggesting that only one type of instability mode is dominant for this case. Note that this result is not generally true. For example, as reported in Kegerise et al., ${ }^{16}$ at a lower roughness Reynolds number of 319, both even and odd modes of instability were detected in the roughness wake and were of comparable amplitude.

At the streamwise station of $x=110.6 \mathrm{~mm}$, the measured r.m.s. mass flux and the even mode I eigenfunction are in excellent agreement. Here, the fluctuations are small $(<1 \%)$ and the computed mean flow on which the stability analysis is based matches the measured mean flow. At the streamwise station of $x=136.5 \mathrm{~mm}$, however, there are clear differences between the measured r.m.s. mass flux and the even mode I eigenfunction. Here, the fluctuations are relatively large $(\approx 4 \%)$ and therefore, the measured mean flow has been modified by the Reynolds stresses associated with those fluctuations. A specific result of this nonlinear effect is the thickened shear layer seen in Fig. 4c and the broader vertical region of the measured peak fluctuations seen in Fig. 4d. Despite the quantitative differences between the measured and computed mean flows at this streamwise station, the spatial distribution of the measured r.m.s. mass flux remains qualitatively similar to the even mode I eigenfunction.

The streamwise evolution of the peak r.m.s. mass flux $\left(\mathrm{m}^{\prime} / \mathrm{m}_{e}\right)$ in the wake of the diamond roughness element is shown in Fig. 5. The symbols in the figure denote measured data for a range of selected frequencies. Note that here, and throughout the remainder of the paper, the reported r.m.s. mass-flux values at a given frequency were obtained by integrating the PSD in a $\pm 1 \mathrm{kHz}$ band about the frequency of interest. The most amplified frequency is $100 \mathrm{kHz}$ and the disturbance amplitudes for all frequencies saturate at $x=145 \mathrm{~mm}$ and then decay through breakdown. The solid lines in the figure denote the integrated amplitudes of the even mode I instability for the same set of frequencies. For each frequency shown, the stability results were scaled to the amplitudes of the measured data at $x=93.3 \mathrm{~mm}$. The very good agreement between the measured disturbance evolution and that predicted by the stability theory lends further evidence that a single even-mode instability is the primary driver for transition in this case.

\section{B. Circular Roughness Element}

Measurements in the wake of the circular roughness element are presented in this subsection. It should be noted, however, that supporting stability calculations for this case, and the cases to follow, are not currently available and will be presented in a forthcoming paper. Contours of the mean mass flux and the broadband r.m.s. mass flux for five streamwise stations are shown in Fig. 6. The mean flow associated with the circular roughness element wake is qualitatively similar to that for the diamond roughness element. Specifically, the wake contains both low- and high-speed streak structures that extend far downstream of the roughness element (Figs. 6a, c, and e). As we move further downstream, however, the wake flow begins to breakdown and there is increased wall-normal and spanwise spreading of the mean flow (Figs. $6 \mathrm{~g}$ and i). At the last station $(x=179.7 \mathrm{~mm})$, the flow field is becoming more homogeneous in the spanwise direction, although here, there are still remnants of the streaky structures. The footprint of this breakdown process is typically observed in surface-based measurements of heat flux or in oil-flow visualizations as a spreading wedge of turbulent flow. ${ }^{28,29}$ There, streaky structures are also observed to extend well into the turbulent wedge region.

As with the diamond roughness element, the inflectional wall-normal and spanwise profiles associated with the mean flow of the circular roughness element set the stage for an inviscid type of instability. Indeed, in the early wake development (Figs. 6b, d, and f), the broadband disturbance growth tends to be concentrated in regions of maximum wall-normal and spanwise shear. Further downstream, where the wake flow is in the beginning stages of breakdown (Figs. $6 \mathrm{~h}$ and $\mathrm{j}$ ), the disturbance levels decay, and fluctuations have spread in

the spanwise direction to contaminate a wider portion of the measurement region. Furthermore, the peaks of the broadband r.m.s. mass flux have shifted to an off-center location at the last measurement station (Fig. 6j).

To determine the frequencies associated with the wake instabilities, the power spectral densities of the mass-flux fluctuations were examined. Mass flux power spectral densities along the centerline of the circular roughness element wake are shown in Fig. 7. The PSD for each streamwise station shown in the figure is for a wall-normal height corresponding to the peak broadband r.m.s. mass flux along the centerline. The PSD show an unstable band of frequencies, centered around $100 \mathrm{kHz}$, that receive substantial growth with 


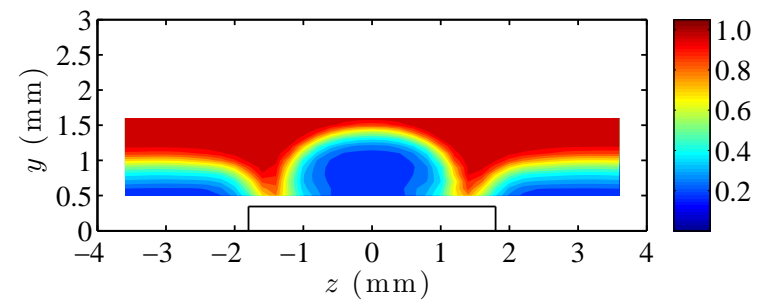

(a) Mean mass flux at $x=102.0 \mathrm{~mm}$.

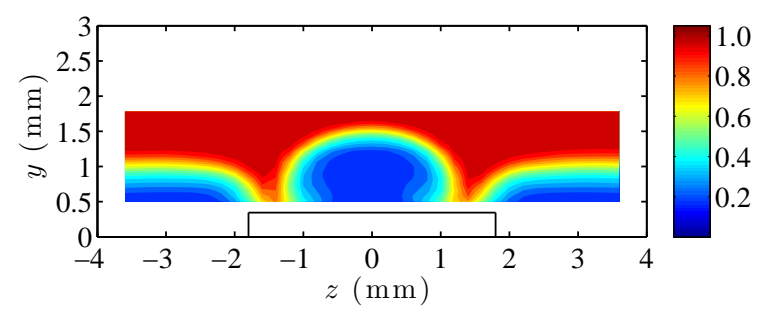

(c) Mean mass flux at $x=110.6 \mathrm{~mm}$.

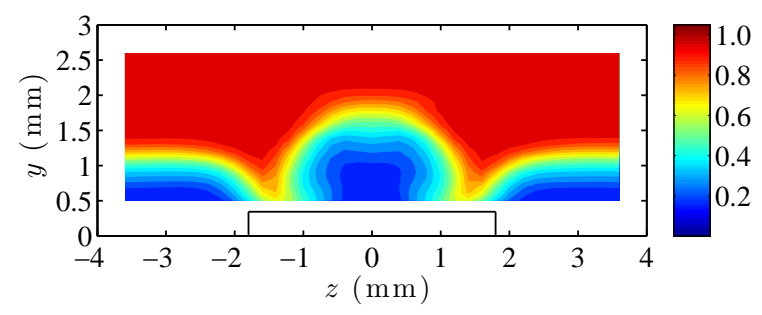

(e) Mean mass flux at $x=136.5 \mathrm{~mm}$.

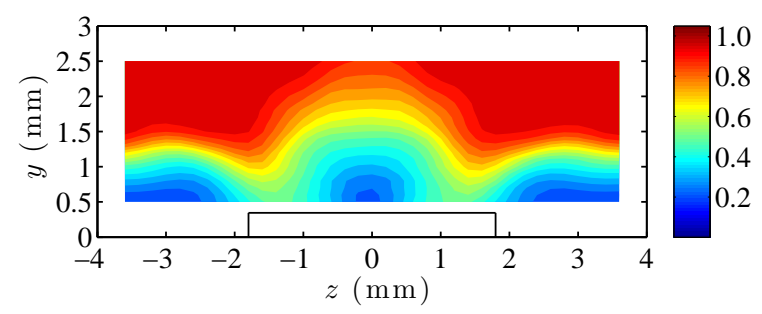

(g) Mean mass flux at $x=153.7 \mathrm{~mm}$.

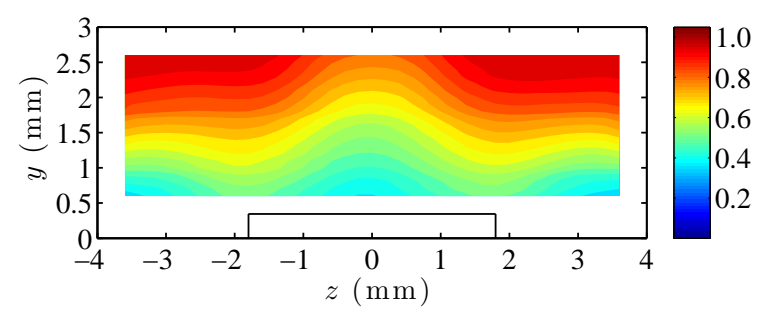

(i) Mean mass flux at $x=179.7 \mathrm{~mm}$.

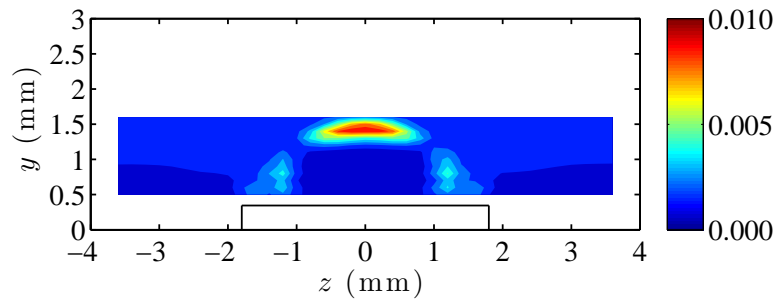

(b) Broadband r.m.s. mass flux at $x=102.0 \mathrm{~mm}$.

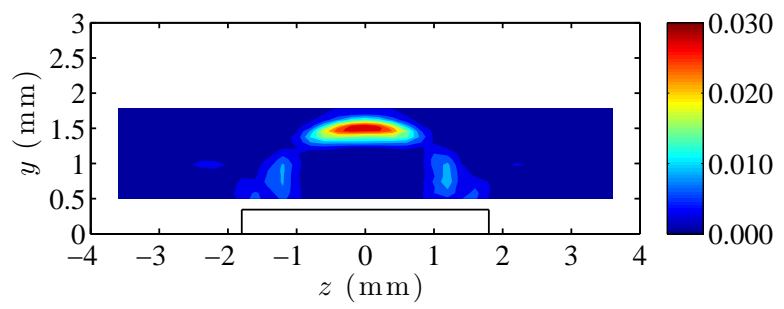

(d) Broadband r.m.s. mass flux at $x=110.6 \mathrm{~mm}$.

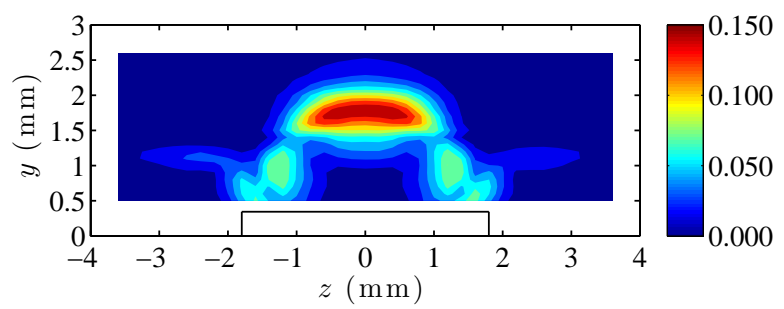

(f) Broadband r.m.s. mass flux at $x=136.5 \mathrm{~mm}$.

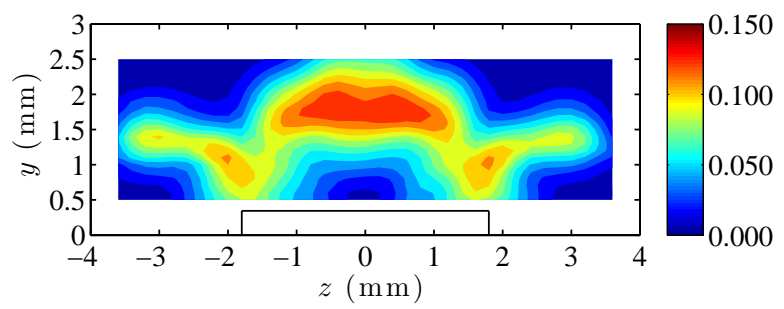

(h) Broadband r.m.s. mass flux at $x=153.7 \mathrm{~mm}$.

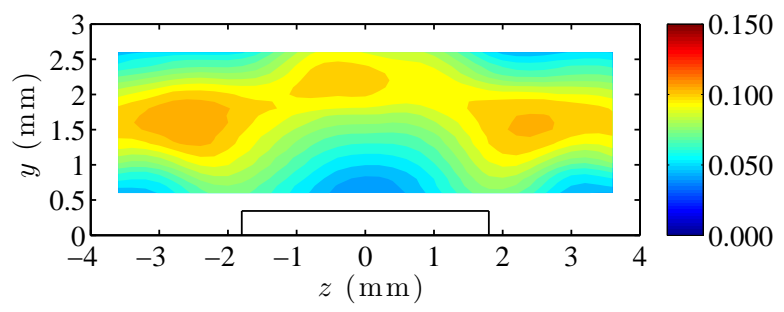

(j) Broadband r.m.s. mass flux at $x=179.7 \mathrm{~mm}$.

Figure 6. Contours of mean mass flux $\left(\bar{m} / m_{e}\right)$ and broadband r.m.s. mass flux $\left(m^{\prime} / m_{e}\right)$ in the wake of the circular roughness element (as viewed from upstream). The black line at the bottom center of each plot represents the projected outline of the roughness element. 


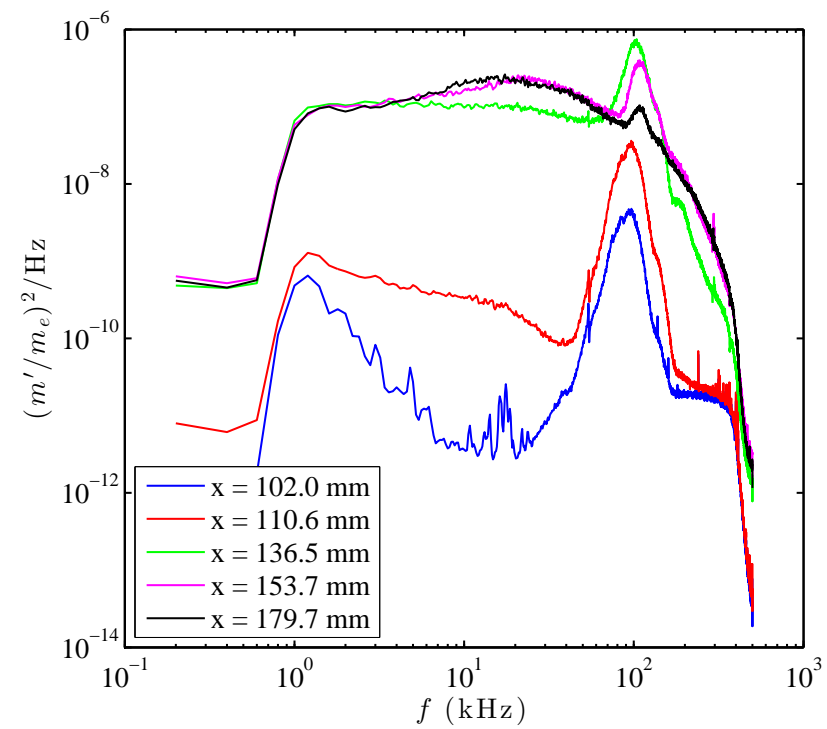

Figure 7. Mass-flux power spectral densities (PSD) along the centerline of the circular roughness element wake. For each streamwise station shown in the plot, the PSD is for a wall-normal height corresponding to the peak broadband r.m.s. mass flux.

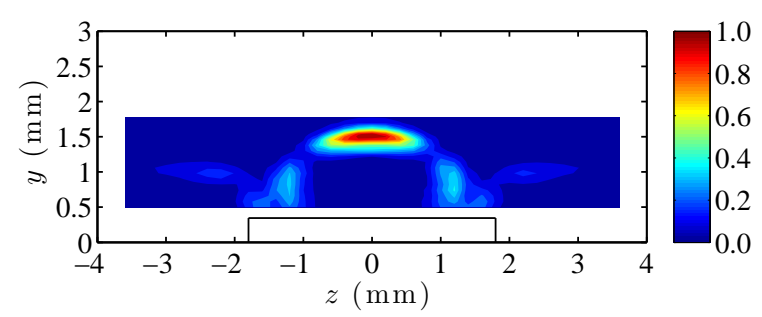

(a) $f=70 \mathrm{kHz}$.

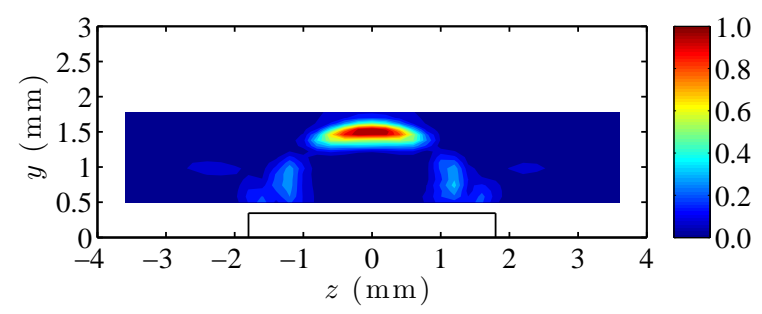

(c) $f=100 \mathrm{kHz}$.

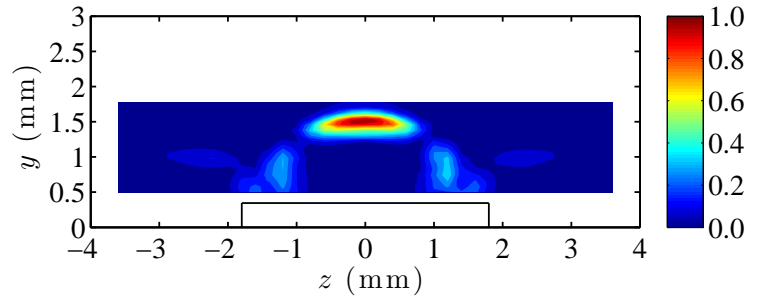

(b) $f=80 \mathrm{kHz}$.

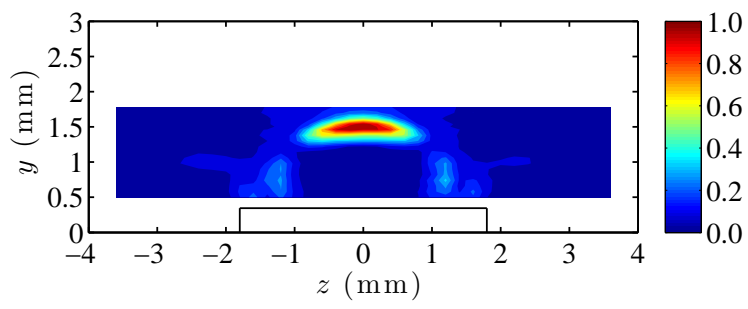

(d) $f=120 \mathrm{kHz}$.

Figure 8. Contour plots of the r.m.s. mass flux $\left(\mathrm{m}^{\prime} / \mathrm{m}_{\max }^{\prime}\right)$ at selected frequencies and for a streamwise station of $x=110.6 \mathrm{~mm}$ in the circular roughness element wake (as viewed from upstream). The black line at the bottom center of each plot represents the projected outline of the roughness element. 


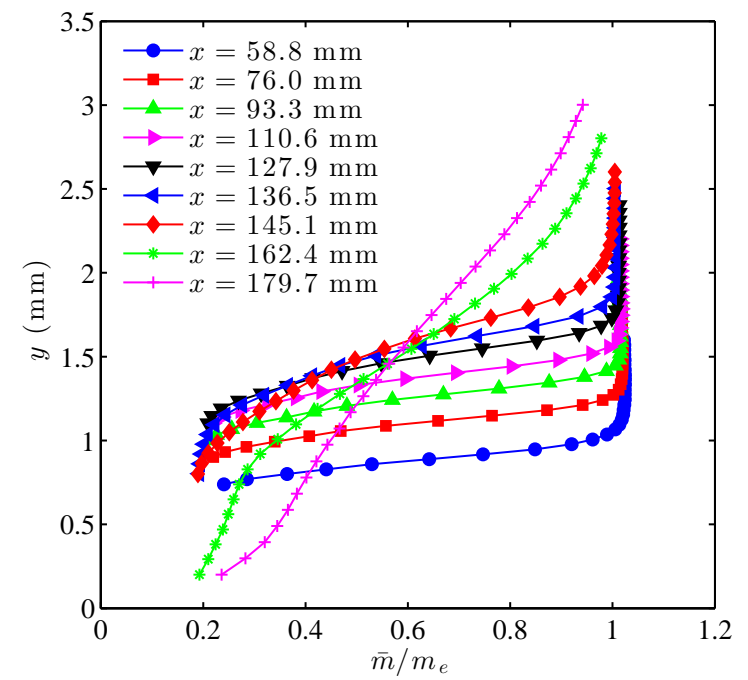

(a) Mean mass-flux profiles along centerline of diamond roughness element wake.

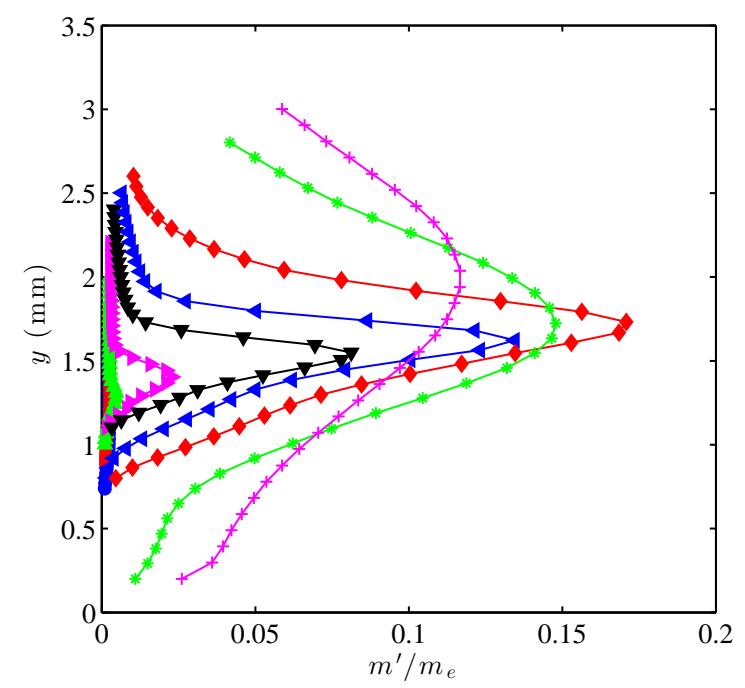

(c) Broadband r.m.s. mass-flux profiles along centerline of diamond roughness element wake.

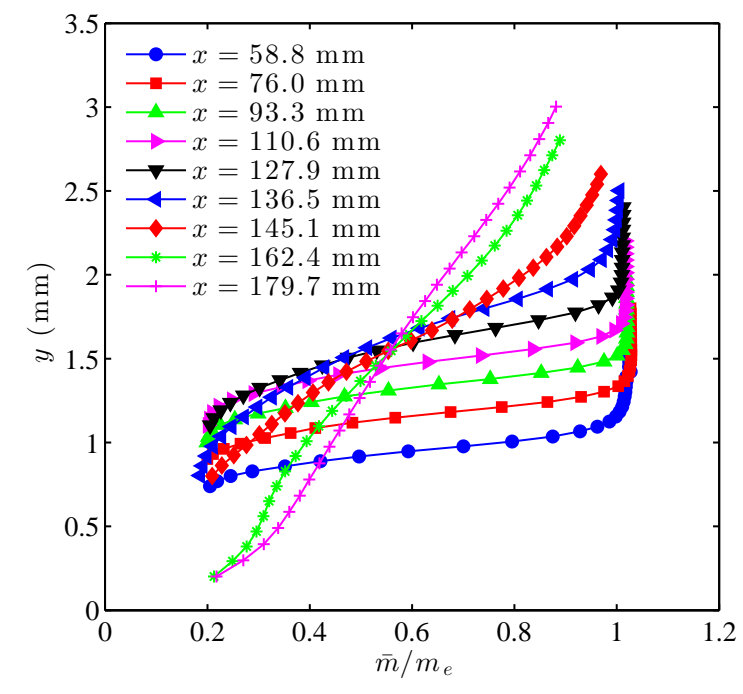

(b) Mean mass-flux profile along centerline of circular roughness element wake.

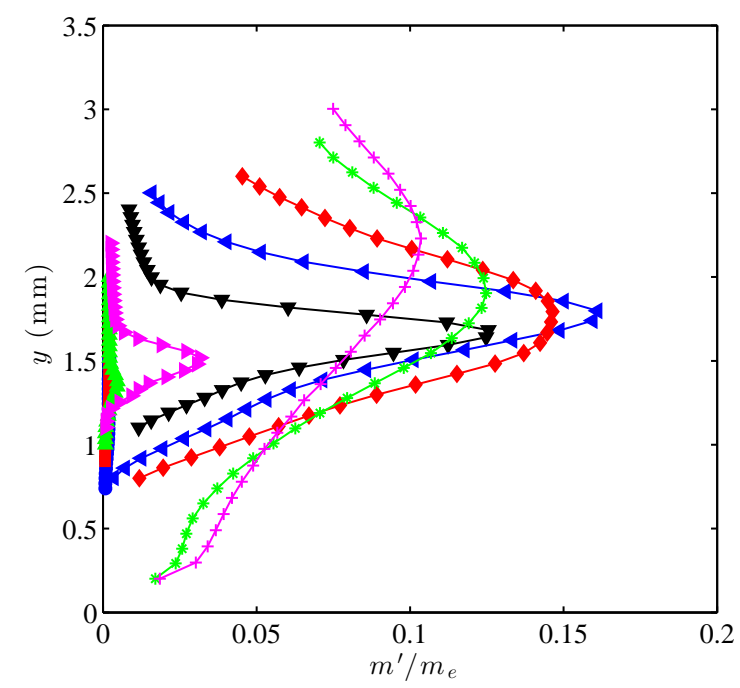

(d) Broadband r.m.s. mass-flux profiles along centerline of circular roughness element wake.

Figure 9. Measured mean and broadband r.m.s. mass-flux profiles along the centerlines of the diamond and circular roughness element wakes.

increasing streamwise distance. The instability growth saturates by $x=136.5 \mathrm{~mm}$ and then decays as we move further downstream. At the last station $(x=179.7 \mathrm{~mm})$, the spectrum is beginning to take on the character of a fully turbulent flow.

Further insight into the instability characteristics can be gained by examining the spatial distribution of the r.m.s. mass flux at selected frequencies. These mode shapes are shown in Fig. 8 for frequencies ranging from $70 \mathrm{kHz}$ to $120 \mathrm{kHz}$ and for a streamwise station of $x=110.6 \mathrm{~mm}$. Here, the selected frequencies are contained in the unstable band of frequencies identified in the PSD of Fig. 7. In general, the mode shapes are similar across the range of frequencies shown, and that similarity suggests a single type of instability mode at this streamwise station. For other streamwise stations, up to where the instability saturates at $x=136.5 \mathrm{~mm}$, the mode shapes were found to be qualitatively similar to those at $x=110.6 \mathrm{~mm}$. Therefore, as in the diamond roughness element case, the transition process for the circular roughness element appears 


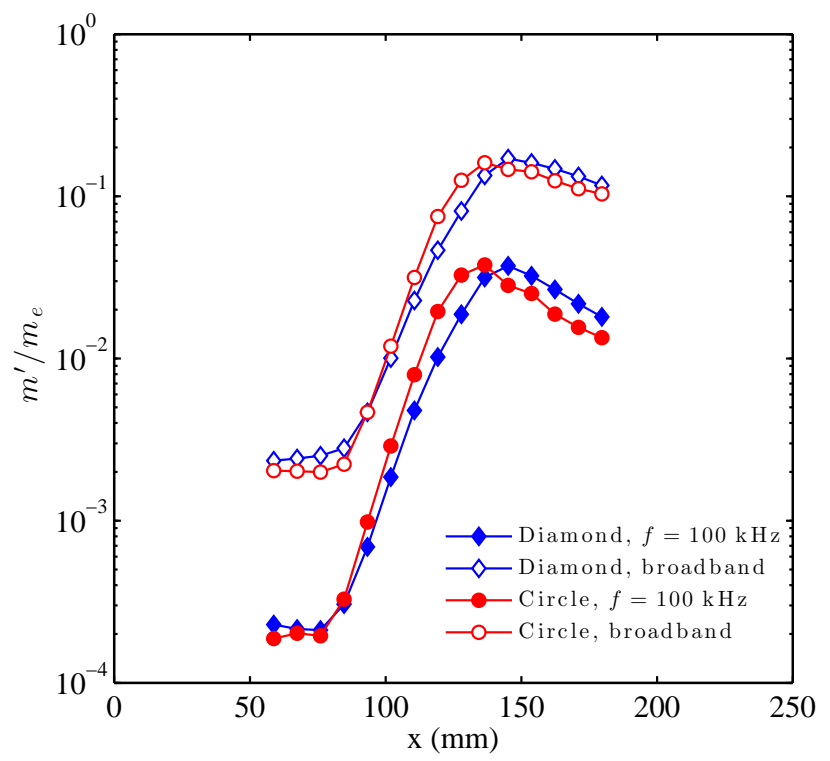

Figure 10. Streamwise evolution of peak r.m.s. mass-flux fluctuations $\left(\mathrm{m}^{\prime} / \mathrm{m}_{e}\right)$ in the diamond and circular roughness element wakes. Data are shown for the broadband r.m.s. and the r.m.s. at the most amplified frequency of $100 \mathrm{kHz}$.

to be driven by a single type of instability mode. Given that the mean flow for the circular roughness element is similar to that for the diamond roughness element, it is reasonable to expect that the instability characteristics will be similar. In particular, the most amplified frequency for both cases is $100 \mathrm{kHz}$ and the measured mode shapes for the circular roughness element wake are qualitatively similar to the dominant even mode I eigenfunction calculated for the diamond roughness element (as shown in Figs. 4b and d).

Although the mean flow and instability characteristics for the diamond and circular roughness elements are similar, there are subtle differences. Mean mass flux and broadband r.m.s. mass-flux profiles along the centerline of both wakes are shown in Fig. 9. In the early development of the wake, both display a lofted shear-layer character with maximum disturbance energy near the maximum $\partial \bar{m} / \partial y$. However, close inspection reveals that the mean mass-flux profiles for the circular roughness element are shifted up relative to those for the diamond roughness element. This suggests that the circular roughness element produces a slightly stronger uplift of low momentum fluid along the wake centerline. The disturbance growth rate for the circular roughness element also appears to be stronger and the disturbances saturate at $x=136.5 \mathrm{~mm}$, while those for the diamond roughness element saturate at $x=145.1 \mathrm{~mm}$. Breakdown of the wake flow, which is observed as a sudden wall-normal spreading of the shear-layer profile, begins near $x=136.5 \mathrm{~mm}$ for the circular roughness element. For the diamond roughness element, it begins near $x=145.1 \mathrm{~mm}$.

The streamwise evolution of peak r.m.s mass flux for the diamond and circular roughness elements is compared in Fig. 10. Here, data are shown for the broadband r.m.s. and the r.m.s. at the most amplified frequency of $100 \mathrm{kHz}$. The growth rate associated with the circular roughness element is clearly larger and as a result, the point at which breakdown to turbulence begins is shifted slightly upstream relative to that for the diamond roughness element. This difference in growth rates for the two cases is most likely linked to the subtle differences observed in the modified mean flows of the two roughness wakes. Note that for both cases, breakdown to turbulence begins at about the same amplitude - approximately $17 \%$ for the broadband r.m.s. mass flux and approximately $4 \%$ for the r.m.s. mass flux at $100 \mathrm{kHz}$ (integrated over a $\pm 1 \mathrm{kHz}$ frequency band).

\section{Right Triangle Roughness Element}

Contours of the mean mass flux and the broadband r.m.s. mass flux at four streamwise stations are shown in Fig. 11. As with the diamond and circular planform geometries, the wake of the right-triangle planform 


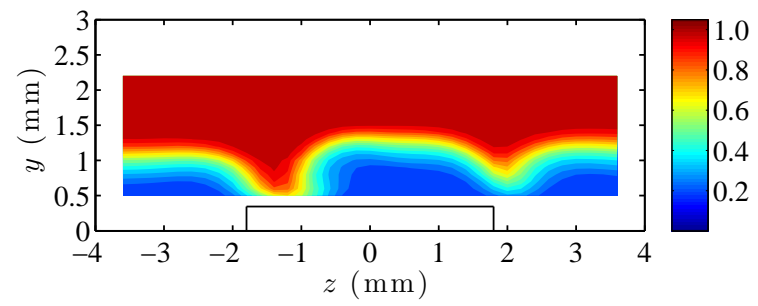

(a) Mean mass flux at $x=136.5 \mathrm{~mm}$.

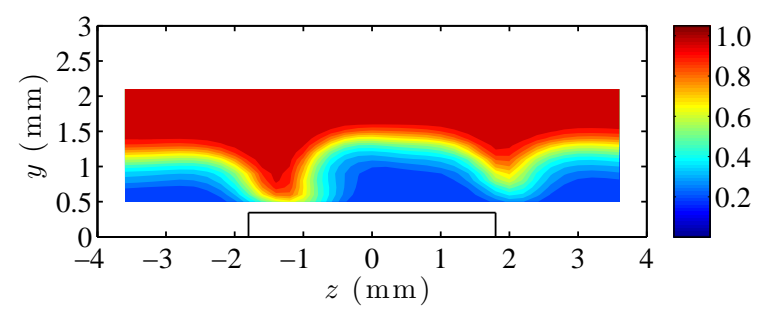

(c) Mean mass flux at $x=153.7 \mathrm{~mm}$.

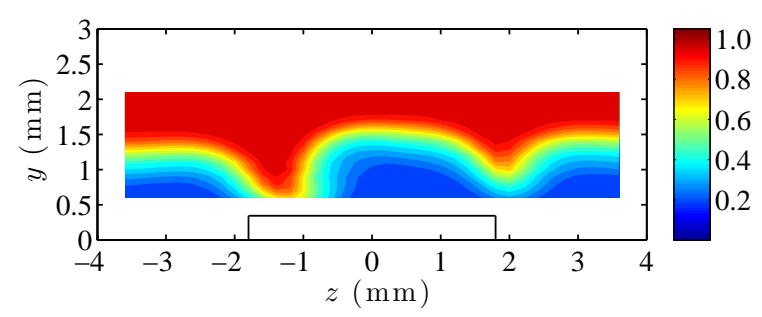

(e) Mean mass flux at $x=179.7 \mathrm{~mm}$.

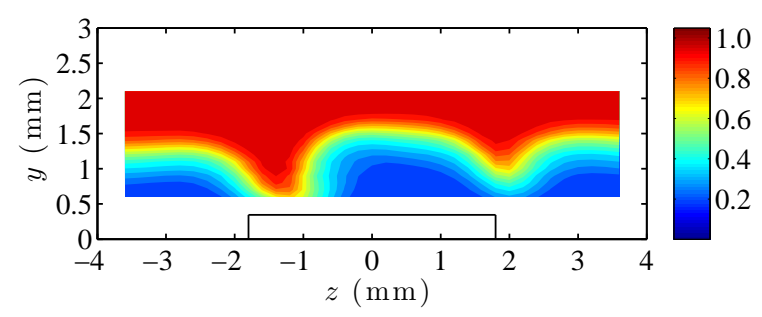

(g) Mean mass flux at $x=205.6 \mathrm{~mm}$.

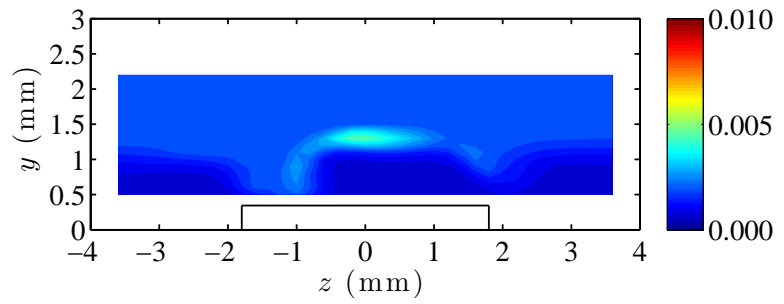

(b) Broadband r.m.s. mass flux at $x=136.5 \mathrm{~mm}$.

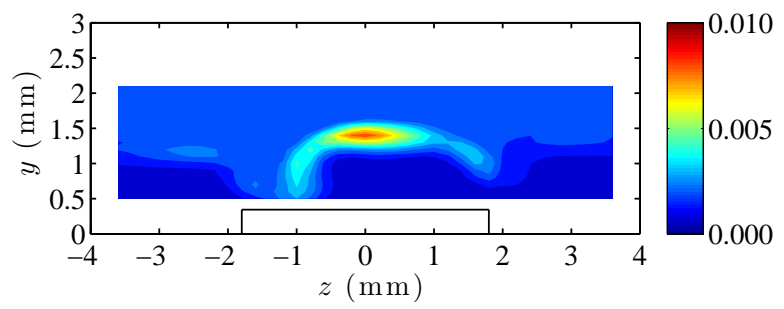

(d) Broadband r.m.s. mass flux at $x=153.7 \mathrm{~mm}$.

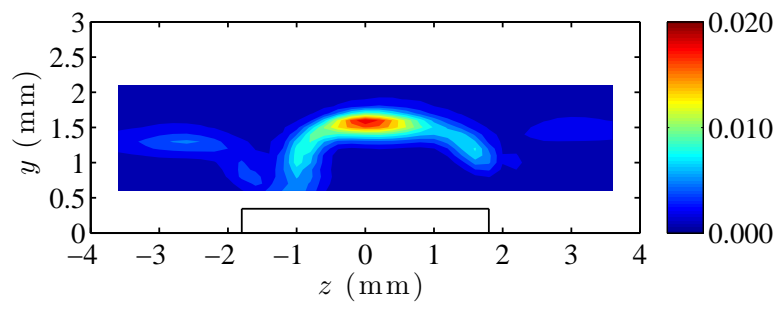

(f) Broadband r.m.s. mass flux at $x=179.7 \mathrm{~mm}$.

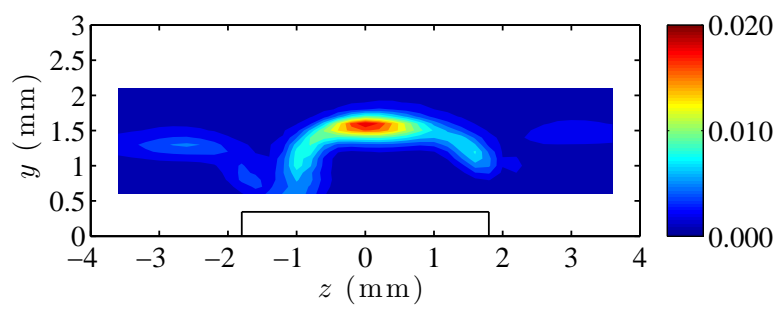

(h) Broadband r.m.s. mass flux at $x=205.6 \mathrm{~mm}$.

Figure 11. Contours of mean mass flux $\left(\bar{m} / m_{e}\right)$ and broadband r.m.s. mass flux $\left(m^{\prime} / m_{e}\right)$ in the wake of the right-triangle roughness element (as viewed from upstream).

exhibits low- and high-speed streak structures. However, the inclination of the upstream edge with respect to the flow direction produces a slight asymmetry in the mean flow. In addition, the uplift of low-momentum fluid behind the roughness element is weaker and broader in extent than that for the diamond and circular planform elements. As before, the disturbance energy in the roughness wake is concentrated in regions of high wall-normal and spanwise shear, but in contrast, the disturbance levels are an order of magnitude less than those observed for the diamond and circular planform elements. Breakdown was not observed over the measurement region considered for this roughness case.

Mass-flux power spectral densities at the peak broadband r.m.s. mass flux for selected streamwise stations along the wake of the right-triangle roughness element are shown in Fig. 12. The spectra display a single band of unstable frequencies centered on $70 \mathrm{kHz}$. At the last streamwise station shown in the figure $(x=205.6 \mathrm{~mm})$, there is growth of disturbance energy around the first harmonic at $140 \mathrm{kHz}$, although it is not yet strong enough to manifest into a distinct peak. Mode shapes for the primary instability band are 


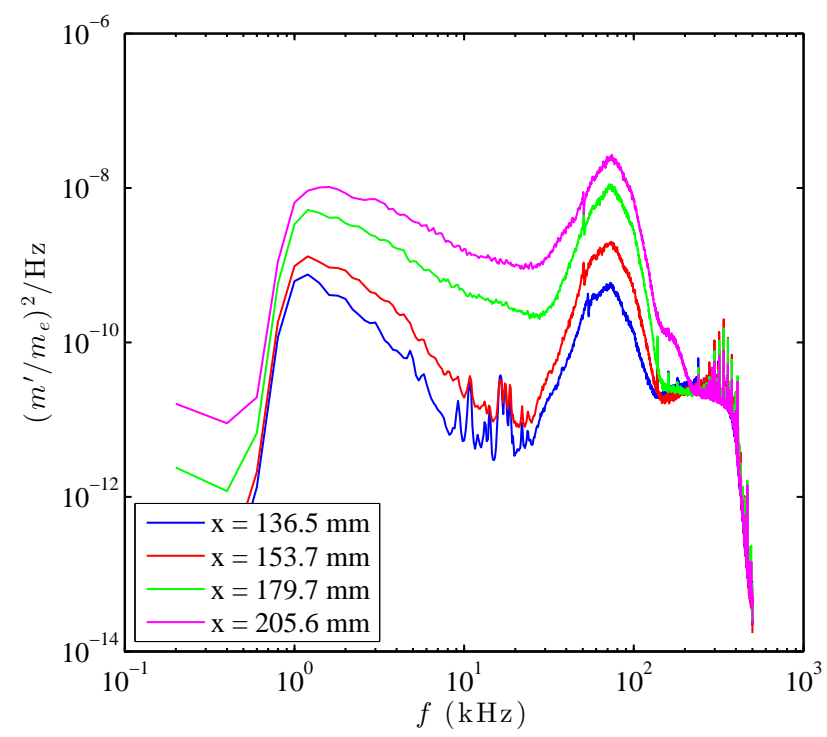

Figure 12. Mass-flux power spectral densities at the peak of the broadband r.m.s. mass flux for selected streamwise stations along the wake of the right-triangle roughness element.

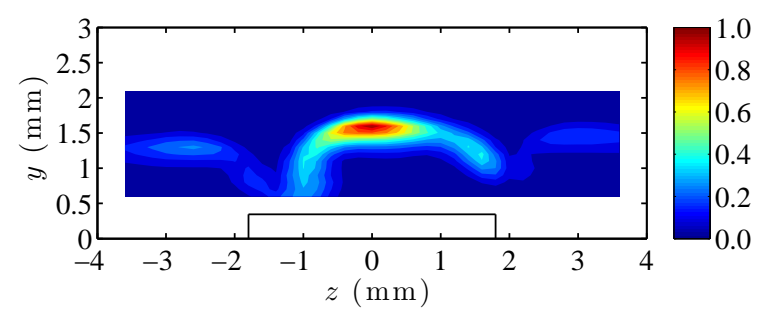

(a) $f=50 \mathrm{kHz}$.

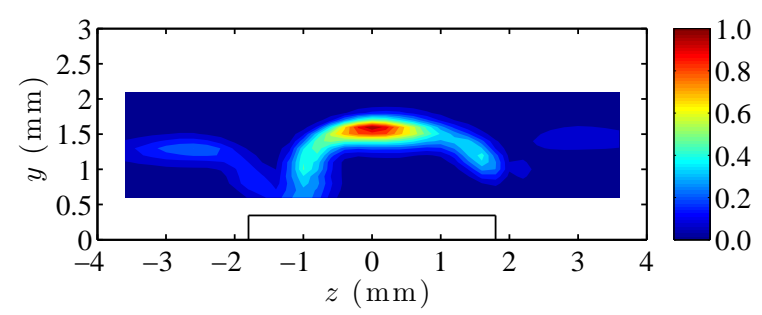

(c) $f=70 \mathrm{kHz}$.

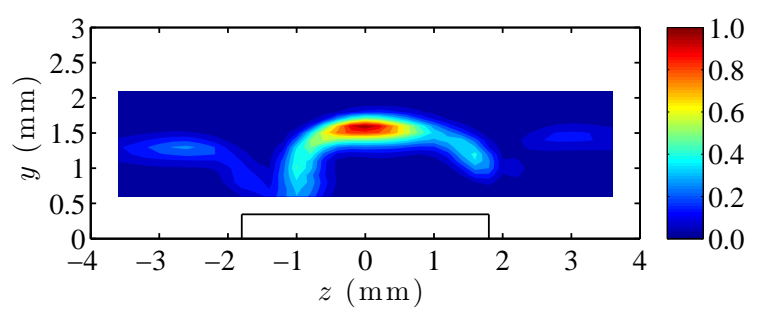

(b) $f=60 \mathrm{kHz}$.

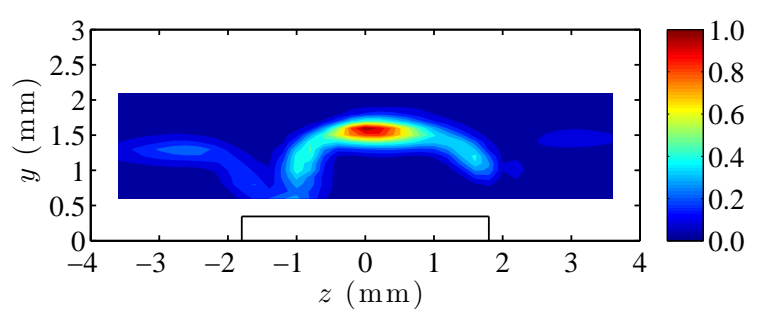

(d) $f=90 \mathrm{kHz}$.

Figure 13. Contour plots of the r.m.s. mass flux $\left(\mathrm{m}^{\prime} / \mathrm{m}_{\max }^{\prime}\right)$ at selected frequencies and for a streamwise station of $x=179.7 \mathrm{~mm}$ in the right-triangle roughness element wake (as viewed from upstream). 
presented in Fig. 13 for frequencies ranging from $50 \mathrm{kHz}$ to $90 \mathrm{kHz}$ and a streamwise station of $x=179.7 \mathrm{~mm}$. As with the previous two roughness cases, the mode shapes are similar across a range of frequencies and for other streamwise stations (not shown here), again suggesting that a single type of instability mode dominates the roughness wake. However, the mode shape in the present case is different than that for the diamond or circular planform and given the asymmetry in the mean flow, the wake will no longer support even or odd modes of instability. Rather, new families of instability modes will be associated with the asymmetric wake of the right-triangle planform. Stability analysis of the mean flow, which proceeds as it did for the diamond planform case, is currently underway and will be reported in a forthcoming paper.

\section{45-Degree Fence Roughness Element}

Contours of the mean mass flux and the broadband r.m.s. mass flux at five streamwise stations in the wake of the fence roughness are shown in Fig. 14. Here, the mean-flow asymmetry is much stronger than that for the right-triangle roughness case, and the mean-flow contours are reminiscent of the streamwise velocity contours associated with a finite amplitude cross-flow vortex in a three dimensional boundary layer. On the side corresponding to the trailing edge of the fence, there is a prominent uplift of low momentum fluid and a substantial thickening of the boundary layer. On either side of this low-speed streak are high-speed streaks where the local boundary-layer thickness is reduced. The high-speed streak on the leading-edge side is much broader and the boundary layer is much thinner than it is for the high-speed streak on the trailing-edge side. As we move towards the last measurement station shown in the figure, the mean-flow spreading in the wall-normal and spanwise directions indicates the beginning stages of breakdown for the roughness wake. The measured mean-flow contours shown in Fig. 14 are qualitatively similar to those computed by Choudhari et al. ${ }^{5}$ There, they considered a fence roughness element on a flat plate with an edge Mach number of 3.5 and $k / \delta \sim 0.5$. Danehy et al. ${ }^{15}$ also performed an experimental study of fence-type roughness elements on a wedge body with a sharp tip and an edge Mach number of approximately 4 . The roughness height to boundary-layer thickness for their study was $k / \delta \sim 1$. Despite the differences in the flow configurations, nitric oxide (NO) planar laser-induced fluorescence (PLIF) visualizations in their study suggest a similar wake-flow structure. Furthermore, heat-flux measurements on the wall of their model indicate the footprint of the streak structures in the flow. Specifically, low heat flux was observed in a region below where the low-speed streak is expected and high heat flux was observed in regions below where the high-speed streaks are expected.

As with the other roughness cases, the broadband disturbance energy tends to be concentrated in regions of high wall-normal and spanwise shear. In contrast to the other cases, where the peak fluctuations were in the lofted shear-layer region near the wake centerline, the maximum fluctuations for the fence roughness wake are on the right side of the low-speed streak. There is also a prominent peak, although smaller, on the left side of the low-speed streak. It is interesting to note that the NO PLIF visualizations of Danehy et $a l .{ }^{15}$ displayed prominent unsteadiness in the wake region corresponding to the low-speed streak.

Mass-flux power spectral densities at the peak broadband r.m.s. mass flux for selected streamwise stations along the wake of the fence roughness element are shown in Fig. 15. As with the other roughness cases, a single band of unstable frequencies is observed, however, the most amplified frequency is reduced to $60 \mathrm{kHz}$. Mode shapes for this primary instability band are presented in Fig. 16 for frequencies ranging from $50 \mathrm{kHz}$ to $90 \mathrm{kHz}$ and a streamwise station of $x=153.7 \mathrm{~mm}$. Again, a single type of instability mode appears to be dominant, as evidenced by the mode-shape similarity across a range of frequencies and for other streamwise stations (not shown here). The stability analysis for this case is also underway and comparisons between the measured mode shapes and the computed eigenfunctions will be made in a forthcoming paper.

\section{E. Comparison of Results for all Roughness Cases}

The instability growth for all roughness planform geometries is compared in Fig. 17 . Here, the peak r.m.s. mass-flux fluctuations at the most amplified frequency for each case are plotted as a function of streamwise position. As we saw earlier, the disturbance growth for the two symmetric roughness elementsthe diamond and the circular planforms - is comparable, and the most amplified frequency is approximately equal. However, close observation of the data reveals a slightly higher growth rate and an earlier saturation point for the circular planform. For the asymmetric roughness elements, the disturbance growth is significantly less and as a result, transition onset will be delayed. The frequency of the most amplified disturbance is also lower for the asymmetric roughness elements. For the right-triangle roughness element in particular, 


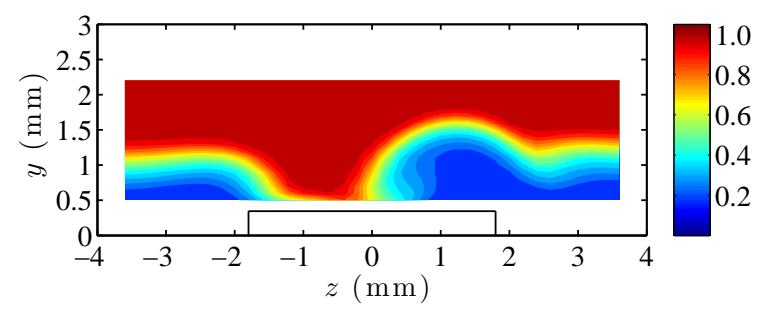

(a) Mean mass flux at $x=136.5 \mathrm{~mm}$.

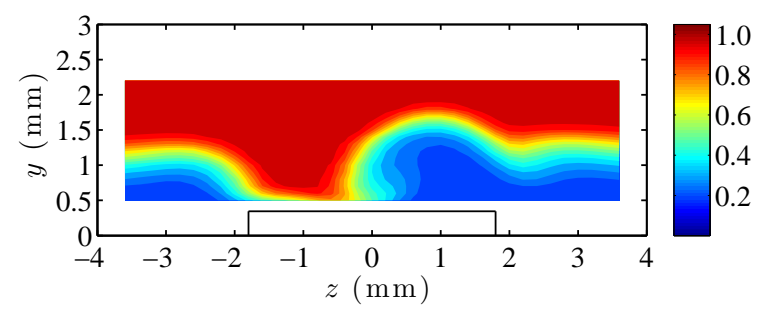

(c) Mean mass flux at $x=153.7 \mathrm{~mm}$.

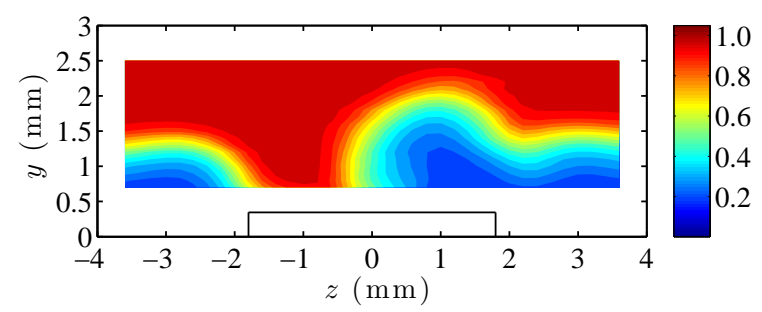

(e) Mean mass flux at $x=188.3 \mathrm{~mm}$.

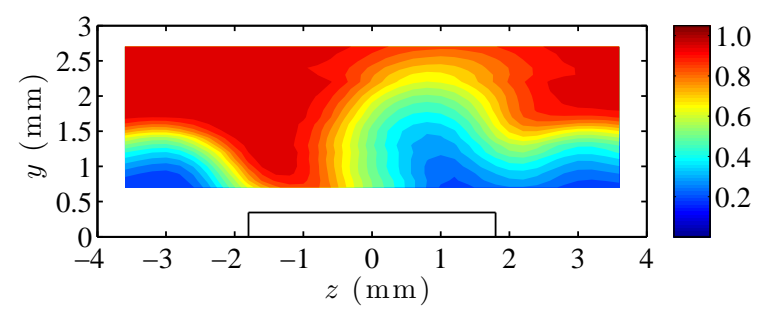

(g) Mean mass flux at $x=205.6 \mathrm{~mm}$.

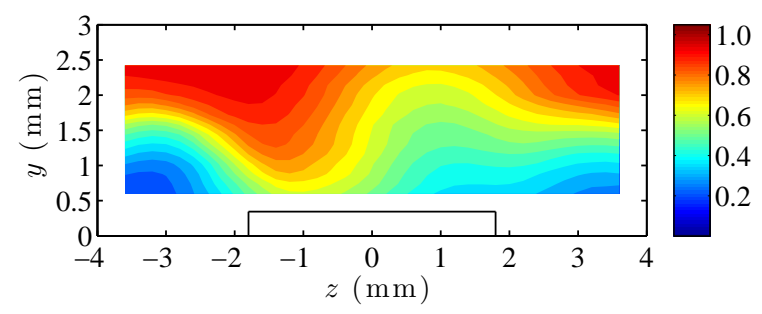

(i) Mean mass flux at $x=231.1 \mathrm{~mm}$.

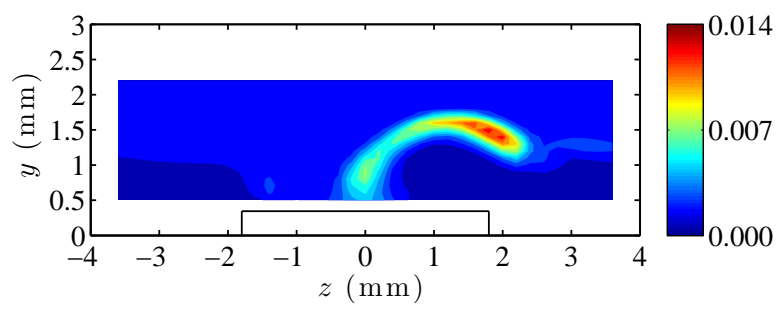

(b) Broadband r.m.s. mass flux at $x=136.5 \mathrm{~mm}$.

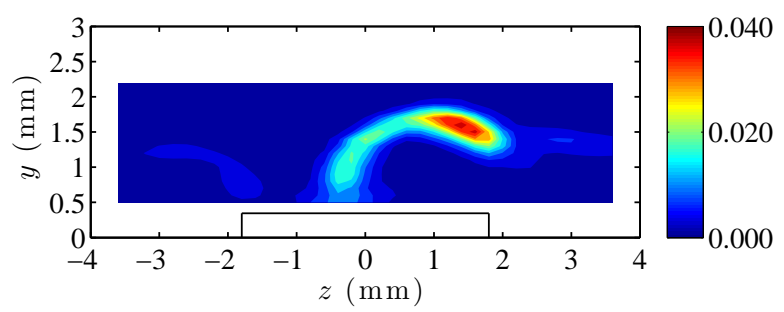

(d) Broadband r.m.s. mass flux at $x=153.7 \mathrm{~mm}$.

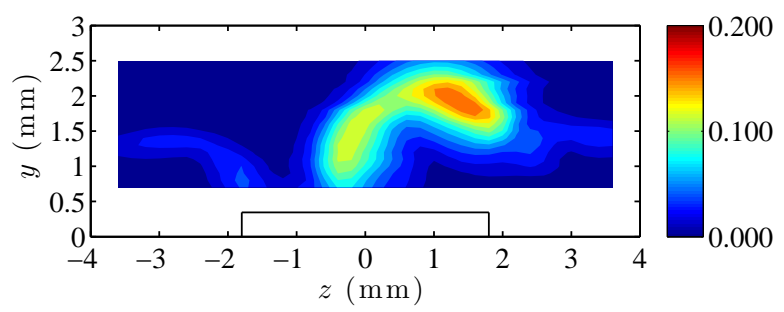

(f) Broadband r.m.s. mass flux at $x=188.3 \mathrm{~mm}$.

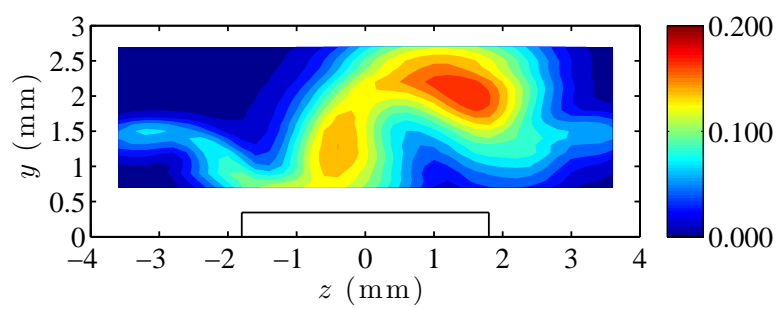

(h) Broadband r.m.s. mass flux at $x=205.6 \mathrm{~mm}$.

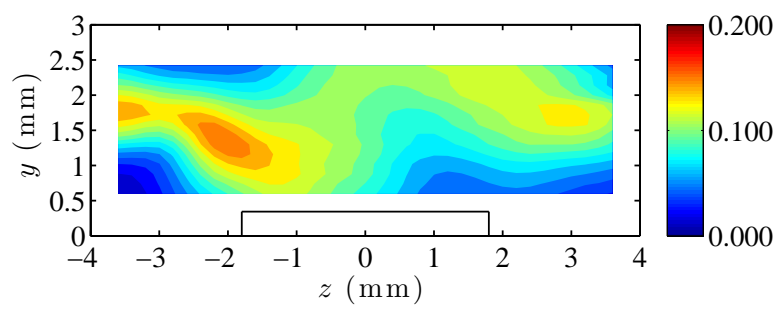

(j) Broadband r.m.s. mass flux at $x=231.1 \mathrm{~mm}$.

Figure 14. Contours of mean mass flux $\left(\bar{m} / m_{e}\right)$ and broadband r.m.s. mass flux $\left(m^{\prime} / m_{e}\right)$ in the wake of the 45-degree fence roughness element (as viewed from upstream). 


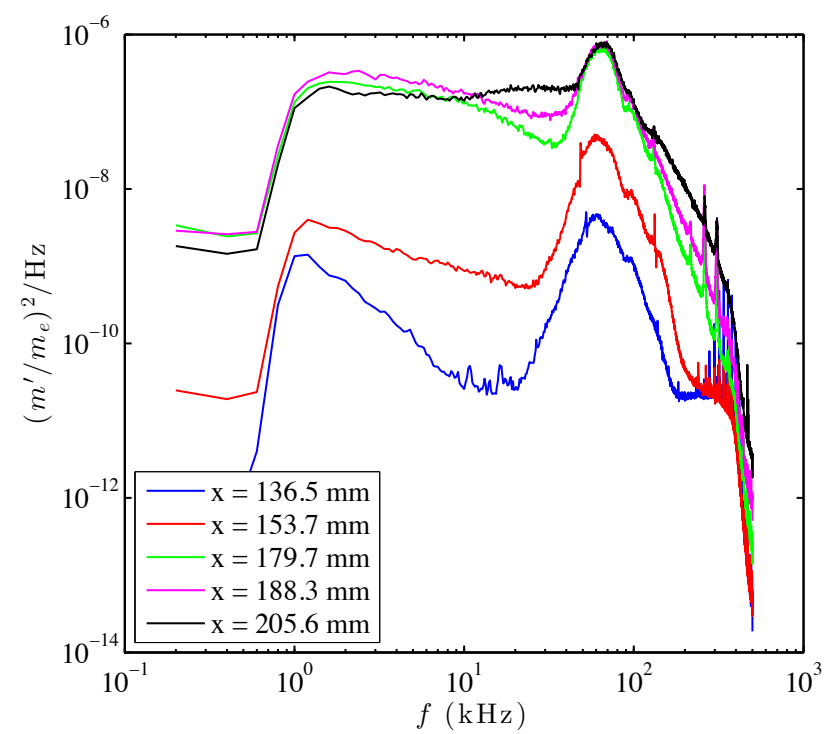

Figure 15. Mass-flux power spectral densities at the peak of the broadband r.m.s. mass flux for selected streamwise stations along the wake of the 45 -degree fence roughness element.

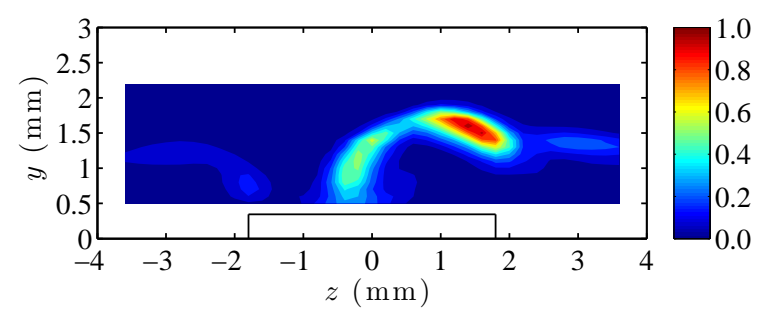

(a) $f=50 \mathrm{kHz}$.

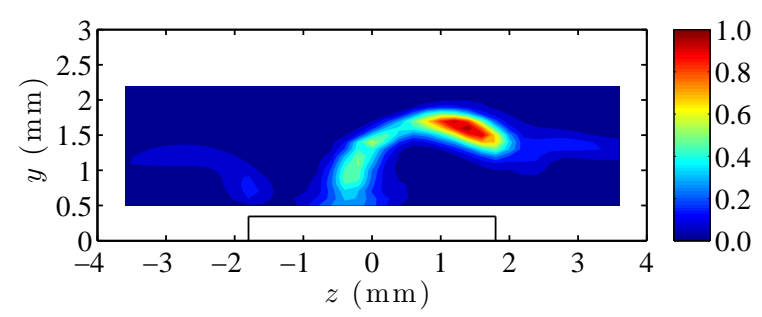

(c) $f=70 \mathrm{kHz}$.

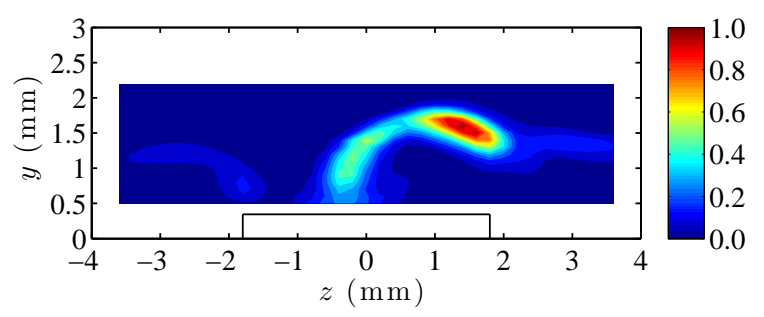

(b) $f=60 \mathrm{kHz}$.

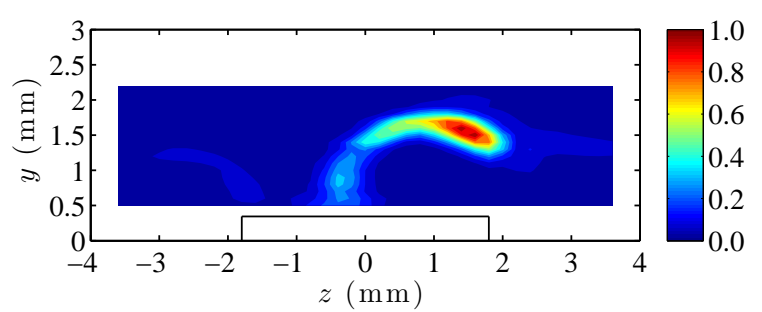

(d) $f=90 \mathrm{kHz}$.

Figure 16. Contour plots of the r.m.s. mass flux $\left(\mathrm{m}^{\prime} / \mathrm{m}_{\max }^{\prime}\right)$ at selected frequencies and for a streamwise station of $x=153.7 \mathrm{~mm}$ in the 45 -degree fence roughness element wake (as viewed from upstream). 


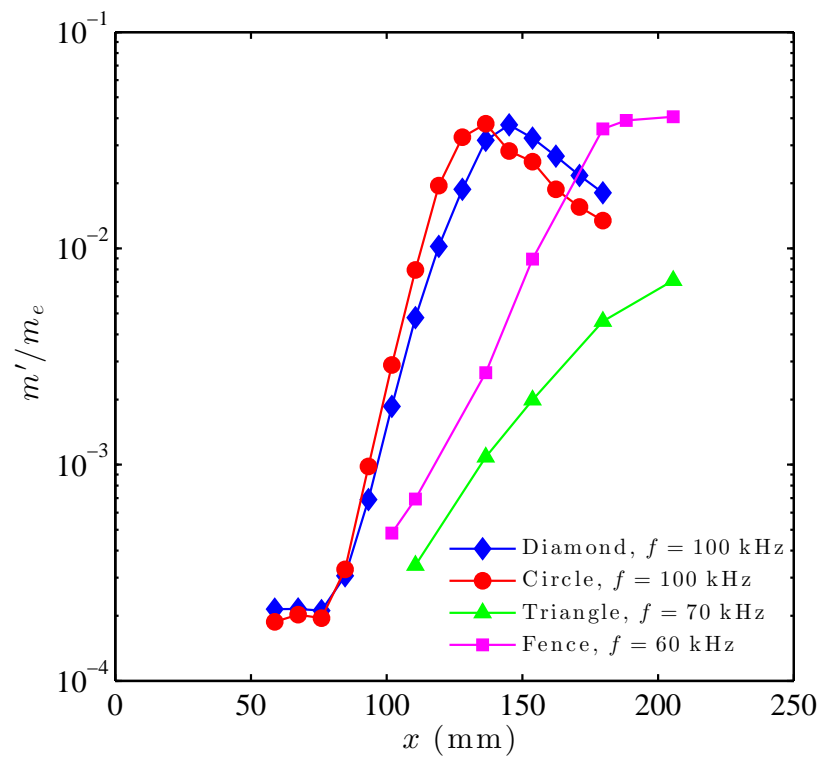

Figure 17. Streamwise evolution of peak r.m.s. mass flux fluctuations $\left(\mathrm{m}^{\prime} / \mathrm{m}_{e}\right)$ in the wake of each roughness case. Data are shown for the most amplified frequency in each case.

the disturbance growth is the lowest, and breakdown was not observed over the streamwise extent of the measurement. For the fence roughness element, the disturbance growth rate is less than that for the symmetric roughness elements, but it is large enough to bring about disturbance saturation and the initial stages of breakdown in the survey region. The delayed transition onset for the asymmetric roughness elements relative to the symmetric roughness elements is consistent with the recent subsonic DNS of Sharma et al. ${ }^{31}$ There, the transition onset location for a rectangular roughness element with the long edge inclined $45^{\circ}$ to the freestream was delayed relative to that for a rectangular roughness element with the long edge perpendicular to the freestream. Finally, the amplitude at which the most amplified disturbance saturates $\left(\mathrm{m}^{\prime} / \mathrm{m}_{e} \approx 4 \%\right.$ in a $\pm 1 \mathrm{kHz}$ band about the frequency of interest), and breakdown begins, is comparable for the diamond, circular, and fence planform geometries. This may provide a useful criterion for an amplitude-based method of transition prediction.

\section{Conclusions}

In this paper, we presented an experimental study of the effects of roughness planform shape on roughnessinduced instabilities in a supersonic laminar boundary layer. Four isolated roughness elements, each with a different planform shape (diamond, circle, right triangle, and $45^{\circ}$ fence), were considered in the study, and the height $(k=346 \mu \mathrm{m})$ and spanwise width $(w=3.6 \mathrm{~mm})$ of each roughness element was held fixed so that a consistent frontal area was presented to the oncoming boundary layer. Detailed mean and dynamic flow-field surveys revealed that the wake flow of each roughness element contains high- and low-speed streaks. In turn, the modified mean flow associated with these streaks supports convective instabilities that are strong enough to bring about breakdown to turbulence. Although the roughness wakes for each case can potentially support multiple families of instability modes, in all planform cases, a single dominant instability mode was observed. This is not expected to be more generally true, as a change in the roughness height or the flow conditions can modify the mean flow and in turn, change the relative strength of the instability modes supported by the wake. For the two symmetric planform shapes - the diamond and circular planforms - the instability mode shapes and disturbance growth rates were found to be similar, and the most amplified disturbance frequency was approximately equal. The similarity in the instability characteristics for these two planforms is likely related to their similar mean-flow characteristics. For the asymmetric planform shapes - the right-triangle and the $45^{\circ}$ fence planforms - the dominant instability mode shapes were asymmetrically distributed about the roughness-wake centerline. The instability growth rate was found to be lower than that for the symmetric 
roughness elements, and the most amplified disturbance frequency was also lower. Due to the lower growth rates for the asymmetric roughness elements, transition onset is delayed relative to that for the symmetric roughness elements.

Collectively, the present measurements for various roughness shapes strongly support the theoretical notion that streak instabilities are the primary transition mechanism for isolated roughness and pave the way for physics-based predictions of roughness induced bypass transition in high-speed boundary layers. Future work will focus on stability analysis for the circular, right-triangle and $45^{\circ}$ fence planform geometries and the present data will be used for validation of that analysis.

\title{
References
}

\author{
${ }^{1}$ McGinley, C. B., Berry, S. A., Kinder, G. R., Barnwell, M., Wang, K. C., and Kirk, B. S., "Review of Orbiter Flight \\ Boundary Layer Transition Data," AIAA Paper 2006-2921, June 2006. \\ ${ }^{2}$ Berry, S. A., Auslender, A. H., Dilley, A. D., and Calleja, J. F., "Hypersonic Boundary-Layer Trip Development for \\ Hyper-X," Journal of Spacecraft and Rockets, Vol. 38, No. 6, November-December 2001, pp. 853-864. \\ ${ }^{3}$ Reda, D. C., "Review and Synthesis of Roughness-Dominated Transition Correlations for Reentry Applications," Journal \\ of Spacecraft and Rockets, Vol. 39, No. 2, March-April 2002, pp. 161-167. \\ ${ }^{4}$ Schneider, S. P., "Effects of roughness on hypersonic boundary-layer transition," Journal of Spacecraft and Rockets, \\ Vol. 45, No. 2, March-April 2008, pp. 193-209. \\ ${ }^{5}$ Choudhari, M., Li, F., Wu, M., Chang, C., Edwards, J., Kegerise, M., and King, R., "Laminar-Turbulent Transition \\ behind Discrete Roughness Elements in a High-Speed Boundary Layer," AIAA Paper 2010-1575, January 2010. \\ ${ }^{6}$ Redford, J. A., Sandham, N. D., and Roberts, G. T., "Compressibility Effects on Boundary-Layer Transition Induced by \\ an Isolated Roughness Element," AIAA Journal, Vol. 48, No. 12, December 2010, pp. 2818-2830. \\ ${ }^{7}$ Bartkowicz, M. D., Subbareddy, P. K., and Candler, G. V., "Numerical Simulations of Roughness Induced Instability in \\ the Purdue Mach 6 Wind Tunnel," AIAA Paper 2010-4723, June 2010. \\ ${ }^{8}$ Iyer, P. S., Muppidi, S., and Mahesh, K., "Transition of Hypersonic Flow Past Flat Plate with Roughness Elements," \\ AIAA Paper 2010-5015, June 2010. \\ ${ }^{9}$ Iyer, P. S., Muppidi, S., and Mahesh, K., "Boundary Layer Transition in High-Speed Flows due to Roughness," AIAA
} Paper 2012-1106, January 2012.

${ }^{10}$ Bernardini, M., Pirozzoli, S., and Orlandi, P., "Compressibility Effects on Roughness-Induced Boundary Layer Transition," Inter. J. Heat and Fluid Flow, Vol. 35, June 2012, pp. 45-51.

${ }^{11}$ Choudhari, M., Li, F., Chang, C., Norris, A., and Edwards, J., "Wake Instabilities behind Discrete Roughness Elements in High Speed Boundary Layers," AIAA Paper 2013-81, January 2013.

${ }^{12}$ Balakumar, P. and Kegerise, M. A., "Roughness-Induced Transition in a Supersonic Boundary Layer," AIAA Paper 2013-3105, June 2013.

${ }^{13}$ Duan, Z., Xiao, Z., and Fu, S., "Direct Numerical Simulation of Hypersonic Transition Induced by Ramp Roughness Elements," AIAA Paper 2014-237, January 2014.

${ }^{14}$ Kegerise, M. A., Owens, L. R., and King, R. A., "High-Speed Boundary-Layer Transition Induced by an Isolated Roughness Element," AIAA Paper 2010-4999, June 2010.

${ }^{15}$ Danehy, P. M., Ivey, C. B., Bathel, B. F., Inman, J. A., Jones, S. B., Watkins, A. N., Goodman, K. Z., McCrea, A. C., Leighty, B. D., Lipford, W. K., Jiang, N., Webster, M., Lempert, W., Miller, J., and Meyer, T., "Orbiter BLT Flight Experiment Wind Tunnel Simulations: Nearfield Flow Imaging and Surface Thermography," AIAA Paper 2010-1571, January 2010.

${ }^{16}$ Kegerise, M. A., King, R. A., Owens, L. R., Choudhari, M., Norris, A., Li, F., and Chang, C., "An Experimental and Numerical Study of Roughness-Induced Instabilities in a Mach 3.5 Boundary Layer," AVT Specialists Meeting on Hypersonic Laminar-Turbulent Transition, San Diego, CA, April 16-19, 2012.

${ }^{17}$ Wheaton, B. M. and Schneider, S. P., "Roughness-Induced Instability in a Hypersonic Laminar Boundary Layer," AIAA Journal, Vol. 50, No. 6, June 2012, pp. 1245-1256.

${ }^{18}$ Wheaton, B. M. and Schneider, S. P., "Instability and Transition due to Near-Critical Roughness in a Hypersonic Laminar Boundary Layer," AIAA Paper 2013-84, January 2013.

${ }^{19}$ Bathel, B. F., Iyer, P. S., Mahesh, K., Danehy, P. M., Inman, J. A., Jones, S. B., and Johansen, C. T., "Comparing Experiment and Computation of Hypersonic Laminar Boundary Layers with Isolated Roughness," AIAA Paper 2014-236, January 2014.

${ }^{20}$ Borg, M. P. and Schneider, S. P., "Effect of Freestream Noise on Roughness-Induced Transition for the X-51A Forebody," Journal of Spacecraft and Rockets, Vol. 45, No. 6, Nov.-Dec. 2008, pp. 1106-1116.

${ }^{21}$ Casper, K. M., Johnson, H. B., and Schneider, S. P., "Effect of Freestream Noise on Roughness-Induced Transition for a Slender Cone," Journal of Spacecraft and Rockets, Vol. 48, No. 3, May-June 2011, pp. 406-413.

${ }^{22}$ Chang, C., Choudhari, M., and Li, F., "Numerical Computations of Hypersonic Boundary-Layer over Surface Irregularities," AIAA Paper 2010-1572, January.

${ }^{23}$ Choudhari, M., Li, F., and Edwards, J. A., "Stability Analysis of Roughness Array Wake in a High-Speed Boundary Layer," AIAA Paper 2009-170, January 2009.

${ }^{24}$ Beckwith, I. E., Creel, T. R., Chen, F.-J., and Kendall, J. M., "Free-Stream Noise and Transition Measurements on a Cone in a Mach 3.5 Pilot Low-Disturbance Tunnel," NASA TP 2180, September 1983.

${ }^{25}$ Chen, F.-J., "Boundary-Layer Transition Extent Measurements on a Cone and Flat Plate at Mach 3.5," AIAA Paper 93-0342, January 1993 
${ }^{26}$ Smits, A. J., Hayakawa, K., and Muck, K. C., "Constant Temperature Hot-Wire Anemometer Practice in Supersonic Flows, Part 1: The Normal Wire," Experiments in Fluids, Vol. 1, 1983, pp. 83-92.

${ }^{27}$ Laufer, J. and McClellan, R., "Measurements of heat transfer from fine wires in supersonic flows," Journal of Fluid Mechanics, Vol. 1, January 1956, pp. 276-289.

${ }^{28}$ Gregory, N. and Walker, W. S., "The Effect on Transition of Isolated Surface Excrescences in the Boundary Layer," Aeronautical Research Council, R \& M. No. 2779, 1956.

${ }^{29}$ Tirtey, S. C., Chazot, O., and Walpot, L., "Characterization of hypersonic roughness-induced boundary-layer transition," Experiments in Fluids, Vol. 50, 2011, pp. 407-418.

${ }^{30} \mathrm{Li}, \mathrm{F}$. and Choudhari, M., "Spatially Developing Secondary Instabilities and Attachment Line Instability in Supersonic Boundary Layers," AIAA Paper 2008-590, January 2008.

${ }^{31}$ Sharma, A., Drews, S. D., Kuester, M., Goldstein, D. B., and White, E. B., "Evolution of Disturbances Due to Discrete and Distributed Surface Roughness in Initially Laminar Boundary Layers," AIAA Paper 2014-235, January 2014. 